This paper was presented at the South Pacific Regional Conference on Earthquake Engineering, held in Wellington, N.Z., May, 1975.

\title{
SEPARATION OF NON-STRUCTURAL COMPONENTS IN BUILDINGS
}

\author{
O. A. Glogau*
}

\section{SYNOPSIS}

The greatest monetary loss arising from the action of earthquakes on modern buildings is that due to non-structural damage. The causes of this non-structural damage are firstly the low damping characteristics of modern structures and secondly the lack of adequate separation of rigid non-structural elements and the materials used for their fabrication. Of no less significance are the hazards that have been created to people in and around buildings by the failure of non-structural elements. Frequently the lack of adequate separation has resulted in serious damage or failure of the structure itself.

The author compares theoretical response and deformation of structures with recent N.Z. earthquake evidence and with current and proposed code requirements.

Significant reduction in expense and simplification of separation details can be achieved at the planning stage. Examples of practical details dealing with cladding panels, windows, curtain walls, partitions and stairs are given.

The problem of ensuring that the designers intentions are carried out on site are discussed, difficulties experienced are reported and suggestions for minimising such problems are made.

\subsection{INTRODUCTION}

The concept that protection against nonstructural damage is part of the design process is relatively new. There are a number of reasons for this. Firstly, until recently our knowledge of earthquake engineering was so limited that aseismic design was considered to have been entirely successful if survival in the face of these mysterious and apparently entirely unsystematic cataclysmic forces was achieved. Secondly, the most successful aseismic structures of yesterday were relatively low, walled buildings with strengths far in excess of code minimum and these had certain built-in features that automatically limit non-structural damage, provided serious structural damage does not occur. This type of structure has a high potential for damping, suffers relatively small deformation prior to failure.

The demand for higher structures and changes in architectural style led to the development of framed structures which have totally different characteristics. They have inherently little damping, a longer fundamental period and depend on large

* Chief Structural Engineer, New Zealand Ministry of Works and Development. inelastic displacements for their survival in earthquakes. It will be shown that the design of this type of structure, both from economic and safety reasons should include consideration of non-structural damage.

\subsection{OBJECTIVES}

The objective of the separation of nonstructural components in buildings is to:

(ii) minimise damage in severe earthquakes and thereby prevent possible panic or injury and loss of life to persons in and around buildings.

(iii) prevent non-structural components from adversely altering the intended performance of the structure.

Detailing should be such that in case damage occurs restoration can be carried out readily. These objectives must be achieved while taking into consideration function, appearance and cost.

\subsection{EVIDENCE FROM RECENT EARTHQUAKE DAMAGE}

The reference point for all our efforts in earthquake resistant design must be earthquake damage or the lack of it. Modern framed structures as a structural type have increasingly revealed themselves as having great potential for non-structural damage. Fig. I showing the interior of the Banco Central following the 1972 Managua earthquake illustrates the point. Even in countries such as New Zealand, where government insurance is intended to replace all of the direct economic loss due to building damage "business won't be as usual" for a considerable time in a building where inadequate attention has been given to the control of non-structural damage.

Non-structural damage frequently involves a high degree of life hazard. Fig. 2 is from the 1964 Anchorage, Alaska, earthquake. The type of damage shown in Fig. 3 from Managua also occurred at Anchorage where 4" masonry walls fell into stairwells.

Non-structural elements can result in structural failure of the primary system if they attract loads to parts of the structure not designed to resist it. Rigid elements such as masonry partitions or infilling walls, even if relatively weak, are able to alter drastically the intended performance of a structure. In a ductile frame structure it is particularly important to bear in mind that the deformation in a severe earthquake will be a multiple of that computed from code loadings. The designer thus needs to consider the consequences if rigid partitions become shear walls even though separated as per code requirements. For example, the 
structure may form column hinge mechanisms or suffer greatly increased axial loads as occurred during the 1967 Caracas earthquake. The columns of the Macuto Sheraton, although over $\mathrm{Im}$ in diameter were seriously damaged in the mezzanine lobby due to the presence of weak hollow masonry infilling walls above. Fig. 4 .

The consequences of partition walls extending only part height between some columns may be serious. A common example are walls with clerestorey windows. Not only may a higher than intended shear be attracted to these stiffer frames but worse, the column behaviour because of their reduced slenderness is likely to change from a flexural to a shear failing type. Examples include the damage to the Annexe to the Hotel Hilton, Acapulco, Mexico 1962 earthquake (1), the Lorenzo Arenas Market, Conception Chile 1960 earthquake, etc.

A further undesirable effect of nonseparated non-structural elements may be unintended building torsions.

Non-separated rigid elements in a structure have a beneficial effect on its damping characteristics, but, in most instances, this advantage cannot be properly realised because of the structural designers lack of control over the arrangement of these elements at the design stage and even more so during the life of the building. Building owners are not usually aware of the effect of removal or rearrangement of partitions at some stage during the life of the building.

\subsection{RESPONSE OF BUILDINGS}

\subsection{Theoretical Considerations of Response}

The response of a building depends on -

1. Its natural periods of vibration

2. Characteristics of the earthquake motion

3. Damping of the structure

4. Manner in which seismic energy is dissipated.

Very little reliable information is available on damping values. One of the reasons is that damping is not a constant, it being very low for most types of structures during small responses. but increasing with response and damage. For some modern structures, e.g. welded structural steel with light-weight fire proofing and carefully detailed separated elements, damping may be expected to be as low as 1 to $2 \%$ in a moderate earthquake to which the structure responds elastically. For this type of structure damping may not increase significantly even in strong motions.

Two recent draft codes (2) (3) gave $2 \%$ as the value applicable to this type of structure. For framed buildings with separated non-structural elements appropriate damping values which may apply are 2 to $3 \%$ for moderate earthquakes increasing to from 5 to $7 \%$ in strong earthquakes. Reinforced concrete shear wall buildings probably have 3 to $5 \%$ damping in moderate earthquakes rising to possibly $10 \%$ in strong motions. The amplification of ground motions for a given damping value is a very important parameter in evaluating the response of a structure but as Fig. 8 indicates the various authors are by no means agreed upon the appropriate values. For purposes of the following the values recommended by Skinner (4) which are between those of Newmark (5) and Housner (6) have been used.

In order to evaluate the potential for damage in structures designed in accordance with DZ 4203 (7) as Class III in seismic Zone $A$ and also those designed in accordance with the present NZS 1900 Chapter 8, 1965, table $I$ has been prepared.

It will be recalled that DZ 4203 requires elements to have sufficient clearances to allow the structure to deform under an applied horizontal load corresponding to

$v \cdot v=\frac{2.0 C I}{C_{d}} C_{d} W_{t}=2.0 \mathrm{CIW}_{t}$

NZS 1900 Chapter 8, 1965 does not require separation of non-structural elements provided the drift does not exceed $1 / 4 \%$ under the current code loading which is $12 \% \mathrm{~g}$ for short period structures Zone $\mathrm{A}$, Class III. Most Class III (private buildings) were designed to just meet this requirement.

In the preparation of the table the following assumptions were made :

(a) The minimum stiffness of N.Z. frame structures is related to the code design level.

(b) The equal displacement criterion applies i.e. overstrength of a building does not affect its displacements which depend only on initial stiffness.

(c) The "Skinner" spectrum represents the ground motion.

The column of the table marked 2 gives an indication of the maximum ground acceleration (for the assumed motion) which may occur without causing damaging deformations i.e. a structure with fundamental period 0.3 sec., $2 \%$ damping and hence amplification 3.2 , will suffer a response corresponding to 3.2 times the ground acceleration. Since a drift provision has been made for a loading of $2 \mathrm{CW}_{t}=2 \times 0.15 \mathrm{~W}_{t}$ the "allowable" ground acceleration $=\frac{2 \times 0.15}{3.2} \mathrm{~W}_{t}=0.094 \mathrm{~W}_{\mathrm{t}}=9 \% \mathrm{~g}$.

If it is assumed that a particular component including its fixings can withstand an additional drift of approximately $1 / 4 \%$ of its height, a value which in practice often corresponds to the deformation of a structure loaded using the shown $\mathrm{V} / \mathrm{W}_{t}$ values, then these components might conceivably remain undamaged under $1.5 \mathrm{x}$ the acceleration given in Col. "2" of the table. Similar reasoning but applied to a structure designed for $1 / 2$ the separation requirements of DZ 4203 gives the values of column " 1 " of table 1 . Again if the components can tolerate $1 / 4 \%$ drifts the values of col. "2" would apply.

Some prediction may also be made with regard to the damage potential in buildings designed to the 1965 code and incorporating elements not separated from the structure but capable of $1 / 4 \%$ deformation. Such 
buildings would need to be stiff enough not to exceed the $1 / 48$ drift allowed by the code at loads slightly less than those given by $V$ in the table. If $5 \%$ damping is assumed $W_{t}$ Col. "I" table I gives ground acceleration of from $6.58 \mathrm{~g}$ to $158 \mathrm{~g}$ as the maximum tolerable for no damage. The higher value would apply to buildings with relatively long structural periods.

It should be pointed out that the apparent discrepancy in the protection afforded to low period structures compared to those with longer periods results from the relatively higher level of the values of the basic design coefficient in the code relative to the skinner spectrum for longer periods compared to those for lower period structures. This is deliberate since earthquake motions are known to exist that are not included in the 1964 Skinner spectrum. The apparently greater protection for long period structures is not real and these are in any case more likely to suffer large drifts.

For a structure with 28 damping designed to DZ 4203 containing separated components which are incapable of withstanding any deformations within themselves damage is likely to occur at ground accelerations of 9 to $25 \% \mathrm{~g}$. If the elements and fixings are assumed to have some "give" the tolerable level of ground acceleration is likely to be $50 \%$ higher, i.e. from $13.5 \% \mathrm{~g}$ to almost $408 \mathrm{~g}$.

The table also reveals another difficulty, that separation of components decreases damping. If we presume the reduction in damping to be say from $5 \%$ to $2 \%$ an increase of up to 408 in displacement may result thus nullifying some of the advantages gained.

Significant benefits from separation are therefore only obtained if the positioning and detailing of the elements is such that even in severe motions damage is localised and life hazard and indirect damage to the structure minimised (refer to section 6.0$)$.

\subsection{Response to recent N.Z. earthquakes}

To compare theoretical predictions with the effect of earthquakes in N.Z. only two suitable records are available. One of these is the Wellington (Palliser) earthquake of 1 November 1968. Magnitude 5.2 epicentre approx. $45 \mathrm{~km}$, depth shallow (less than $33 \mathrm{~km}$ ), ground acceleration approx. $0.1 \mathrm{~g}$ on stiff soils. Although there were some 2000 claims including glass damage most of the damage was minor. It appears that there were few if any low buildings designed as frames in the area that did not incorporate random walls and the presence of these complicated evaluation. Acceleration response spectra indicated peak amplicication factors on stiff soils of 2.3 (5\% damping $T=0.25$ ) and 1.6 ( $10 \%$ damping). The resulting accelerations $23 \%$ and $16 \%$ are higher than those which could be expected to be sustained by non-structural elements in buildings with pure ductile frames (compare with $\mathrm{V} / \mathrm{W}_{t}$ values of table 1 ). On more flexible soils the responses were $40 \%$ higher.

The second record was that obtained at Massey University, Palmerston North, 6
January 1973. This earthquake had a surprisingly large peak ground acceleration at Massey considering its epicentral distance and depth of both approx. $170 \mathrm{~km}$ and magnitude 6.7 .

The buildings are founded on shallow foundations. The underlying soils consist of firm sandy clays, sandy gravels, moderately dense sands, stiff silts in alternating layers to a depth in excess of $100 \mathrm{ft}$. At some $80 \mathrm{ft}$, below the surface moderately dense medium sands are encountered and the water table is some $40 \mathrm{ft}$. below the surface. Typical Raymond $\mathbb{N}$ values for the sands are 40 to 60 , shear strengths about 1.0 to $3.0 \mathrm{k} . \mathrm{s} . \mathrm{p}$. The soil would be regarded as just in the flexible range in terms of the definition given in DZ 4203 . Such a soil would be expected to amplify rock motions, but more flexible soils closer to the epicentre did not amplify the motions to cause damage. Figs. 5 and 6 are acceleration and displacement response spectra for that earthquake. Several identical 4 storey link blocks designed as framed structures with separated nonstructural elements are located between 4 storey very rigid shear wall buildings from which they are separated by 3" gaps (Fig. 7). Scratch marks of flashings at roof level between several blocks gave a clear indication that relative movements of 7/8" took place between the rigid buildings and the link blocks. The link blocks having only 4 columns and $36 \mathrm{ft}$. long beams were relatively flexible and had a computed first mode period of $0.45 \mathrm{sec}$.

Allowing for the uncertainty of computed building period the response to the earthquake is of the right order for 2 to $5 \%$ damping. Notwithstanding the design provisions for separations advanced for an early 1960 design, some non-structural damage was sustained by the architectural bridging materials across the gaps as a result of a communication problem between engineers, architect and builder. The nature of the damage although small, highlights a number of important lessons to be learnt and will therefore be discussed in some detail in 7.5 below.

\subsection{Deformation of structures}

To design the connections of nonstructural elements the deformations of a structure must be evaluated. Individual structures differ of course from each other but certain types have similar characteristics and these are shown in Figs. 9 and 10. While it is generally not economically feasible to provide complete damage protection in severe earthquakes a broad understanding of inelastic deformations is useful. For this reason the likely effect of local inelastic deformations is discussed. Small inexpensive detailing features may then be incorporated to give additional margin against failure, i.e. the connection may be made in such a manner as to allow some deformation.

Excluding diagonally braced structures, there are principally three basic structures capable of significant inelastic deformations in use in this country. Firstly, the ductile frame (Fig. 9) which may be subject to large drifts in any storey. DZ 4203 gives 
the max. allowable drift for ductile frames as $0.01 \mathrm{~h}$ for an applied horizontal load of $2 \mathrm{CIW}_{t}$. This is $2 \frac{1}{2}$ times the (ultimate) code design level of $0.8 \mathrm{CI}$. These structures therefore have an allowable interstorey deformation of $0.01 \mathrm{~h} / \frac{2 \mathrm{CI}}{\mathrm{C}_{\mathrm{d}}}=\frac{0.01 \mathrm{~h}}{2 / \mathrm{SM}}$ at design level. If $S=0.8$ and $M=1$, the limiting deformation $=0.004 \mathrm{~h}$ or $0.58^{\prime \prime}$ for $\mathrm{h}=12^{\prime}$ $(14.7 \mathrm{~mm}$ for $3.7 \mathrm{~m})$.

The figure also shows that damage may be caused not only by drift but also by panel rotation resulting from beam deformation. If we presume that panels are erected when most of the gravity deformation has taken place additional panel rotation due to creep and earthquake just prior to the formation of plastic hinges in a beam gives typical values for $\Delta$ and $\Delta p$ of $0.15 "$ and $3 / 8$ " respectively. Following the formation of plastic hinges in beams not only does beam curvature increase but after several cycles into the inelastic range, wide nonclosing cracks may form near their ends usually in locations between panel fixing bolts. To prevent bolts from being sheared off some "give" is an advantage. Fig. 13.

Ductile cantilever shear walls provide better drift control. For a typical six storey structure of $60,000 \mathrm{sq}$.ft. with two walls of height to width ratio of $2: 1$ (above lowest storey) and $\mathrm{T}=0.33 \mathrm{sec} . \mathrm{h}$ the maximum elastic interstorey drift $\Delta$ h under code loading was only 0.1". The total corresponding horizontal building deflection was $0.45^{\prime \prime}$. However when the deformations of this building were computed using an inelastic numerical integration process for $30 \mathrm{sec}$. of the artificial A2 (16) record, significantly larger deformations occurred. The max. interstorey deflection was approx. 1/2" in each of the 4 top storeys. The total horizontal building deflection was $2 \frac{1}{2}$ ".

It is thus seen that even in low cantilever shear wall buildings damage in the upper stories is likely unless suitable measures are taken.

Buildings with ductile coupled shear walls suffer deformations more akin to those of ductile frames but of smaller magnitudes (Fig. 10b). For a typical ten storey shear core with diagonal reinforcement in the coupling beams $\Delta \mathrm{h}$ was computed to be $0.1 "(0.0007 \mathrm{~h})$ increasing to perhaps $1 / 2$ " in a severe earthquake. The latter figure is approximate and further research is required to confirm the mathematical model.

\subsection{Direct dynamic effects due to building motions}

Fixings and components of structures must be capable of withstanding the high accelerations corresponding to the yield capacity (9) of a structure, if failure or damage due to direct inertia loadings is to be avoided. The loadings prescribed for important non-structural elements in DZ 4203 take account of this effect.

\subsection{DAMAGE CONTROL MEASURES \\ 6.1 Reduction of Deformations}

Structure deformations are the most important single cause of damage to components. Minimising these deformations must therefore naturally be the first aim of control measures. Deformations may be reduced by:

(a) Decreasing the response of a structure, and

(b) Increasing its stiffness.

\section{(a) Reduction of Response}

The parameter of particular interest is displacement. Many displacement response spectra exhibit a linearly increasing relationship between displacement and fundamental period $(6)$. Long period, flexible structures, notwithstanding their low acceleration response to many earthquakes are particularly vulnerable to nonstructural damage. Increasing a structure's period therefore does not solve the problem.

A potentially more effective approach is through the use of energy absorbers below the structure. Indications to date are that substantial reductions in building deformations above the level of the absorbers can be achieved and MWD in co-operation with DSIR are engaged in developing practical applications for buildings. It is hoped that the advantages offered by ductile frames for open planning can be gained through the use of these devices, without incurring the usual penalty in the form of large potentially damaging deformations.

\section{(b) Reduction of Deformation by increasing Building Stiffness}

The most economical way of achieving this is through the use of reinforced concrete shear walls. The penalty for this approach is that stiffness in general increases acceleration response and hence requires a design for high forces. High soil pressures under shear walls and restrictions on the use of space, except where walls are located on the exterior of the building, are other disadvantages.

Devices for limiting deformations of structures, particularly where wind is an added consideration, are in use in Japan. They include "Muto" slit walls, torsion connected stiffening panels, K-braces, etc.

\subsection{Component Layout}

Once a designer has taken all measures available to him within the framework of other constraints to reduce deformations he must attempt to locate vulnerable elements in positions where they can be most effectively and economically protected against structure deformations. The most suitable positions for exterior cladding are those where the plane of the cladding and that of the frames running in the same direction do not intersect, i.e. on either side, but not in line with the columns (Fig. 11). By locating exterior claddings outside or inside column lines provision can easily be made for very large drifts because, excepting at the corners of the building, no large relative displacements between vertical edges of components occur. It is an important feature 
of this arrangement that even if interstorey drifts exceed those allowed for, damage is very localised.

\subsection{DETAILS}

\subsection{Exterior Panels}

Fig. Il shows the side elevation of a building where panels are located inside the column line. The panels are supported at the bottom by concrete projections built into the panel and are held in position by bolts. The upper edges of the panels are free to slide in channels while supported against face loads. Foamed plastic materials are used to fill the erection clearances (Fig. 12). It is of course possible to combine support and holding function in the lower floor brackets but the method employed using corbels or ribs (Fig. 13) allows easier erection. At little expense it gives extra security in case bolts are subjected to high gravity shear stresses or where there is only limited corrosion and/ or fire protection. The detail shown is also capable of accommodating a certain amount of beam deformation. Beam curvature results in some displacements of the top edges of the panels relative to each other. Bolt lengths to underside of cleats should be generous to give flexibility for inelastic longitudinal extension of the beams, should plastic hingeing occur.

Where the plane of the exterior cladding intersects transverse beams, such as is frequently the case where panels are located inside the column line, the top supporting channels should be positioned at a level below these beams (Fig. 14). The wall portion above the panels is fixed between channel and upper storey and thus moves with the upper storey.

Claddings which must be located between columns provides much less scope for economic detailing for damage protection. Present practice generally is to apply the methods given above and allow a space between each column and adjacent cladding panel or window (10). This space may be bridged by flashings or by components which are able to slide into each other. In most instances unsightly or expensive details result if movements of more than $\pm I^{\prime \prime}\left(2 \frac{1}{2} \mathrm{~cm}\right)$ are to be accommodated. A l" provision for movement for a $12^{\prime}$ storey height only equals the separation requirements of DZ 4203 for many structural types. It has been shown that meeting this provision will not prevent damage in any but fairly moderate earthquakes. Where flashings are used employing the "accordion" principle care must be taken that the edges are well fixed, otherwise the stiffness of the flexible portion may exceed the strength of the fixing. Flashings built into rebates may give rise to expensive repairs, particularly if located in not readily accessible positions. Details allowing panels to rock are under development.

Details for panel separation in an industrial type of structure are shown in Figs. 15 and 16 . The plates were faced with a friction reducing material and bolted to the panels. There are two top fixings per panel, the second is not yet in place. Panels may also be hung from the upper storey and allowed to slide at the lower.

In the case of deep panels, drift effects perpendicular to panels become significant. Added freedom for movement can be provided by use of flexible packing in the form of say 'Neoprene' under the supports.

\subsubsection{Panel Connections}

It has been shown that real deformations in all but very moderate earthquakes are far greater than those required by codes or indeed practical to provide for in most buildings. Notwithstanding all available detailing measures there is a significant risk that connections will be subjected to loads additional to inertia loads. DZ 4203 requires panel connections to be designed for a loading of $2 \mathrm{~g}$. In some buildings such loadings may actually occur leaving no margin for deficiencies of any kind. As usual in aseismic design our best approach is to provide safety margins by ductility (toughness).

\section{It is therefore essential that -}

(a) Connections be anchored behind panel reinforcing or better still fastened to it.

(b) By suitable choice of materials and manufacturing methods brittleness in the metal of connections should be avoided including that due to strain ageing of galvanised parts or welding of stainless steel to mild steel.

(c) Corrosion not only due to the direct attack of the elements, leakage and condensation but also due to such effects as crevice corrosion in stainless steel must be avoided.

Many panel connections are built in for the life of the structure and deterioration may thus not be discovered until failure occurs which may be due to seismic or only gravity loads.

Fire protection of exterior connections is important to ensure they will not fail in case of fire thus allowing panels to fall into streets. Connections that are highly stressed due to gravity loads need particular attention. Direct fire protection may be provided by application of suitable materials by spraying or glueing.

\subsection{Windows and Curtain Walls}

Windows, where not part of a curtain wall or built into metal or concrete panels, may be given freedom at vertical edges by allowing the frames to slide into jambs or mullions. If glass is bedded in material that may reasonably be expected to stay flexible for the life of the structure - a difficult requirement - considerable additional drifts can be accommodated. Tests carried out at the University of California, Berkeley for the Division of Architecture, California, indicated that for each pane in a vertical line the drift between head and sill of a sash that could take place without damage was

$$
\Delta=2 \mathrm{c}(1+h / b)
$$

where $c=\min$. all round clearance between sash and glass. $h$ and $b$ are the vertical and horizontal window dimensions respectively. Thus for 2 square windows on top of each other within a storey and $c=\frac{1}{4} "\left(6 \frac{1}{2} \mathrm{~mm}\right)$ - 
146

$$
\begin{aligned}
& \Delta=2 \times 2 \times \frac{1}{4}(1+1)=2^{\prime \prime}(50 \mathrm{~mm}) \\
& \text { For } 1 \text { window of } \mathrm{h} / \mathrm{b}=2
\end{aligned}
$$

$$
\Delta=2 \times \frac{1}{4}(1+2)=1 \frac{1}{2} "(38 \mathrm{~mm})
$$

Additional drift can usually be accommodated due to rotation of the sash frame. It is important to note that for hard glazed windows the drift is reduced to $1 / 3$ to $1 / 10$ or less of the above values. (Refer section 8.0.) Clearance between glass and frame may also be achieved using elastomeric gaskets (i.e. Neoprene). See Fig. 17.

Fig. 18 is an interior view of the upper part of a curtain wall employing the "sliding cupboard door" principle. Here again deep cross beams are avoided by lowering the channel, in which the upper edges of the wall are free to slide, below their level. Curtain wall sections in this example are fixed at the bottom edges. The "take up" of relative movements between side and end wall is achieved at the corner of the building (Fig. 19) by a section that slides into the last vertical member. The corner section (Fig. 20) may be lost in severe earthquakes. Tests should be carried out on various systems to ensure that friction induced forces by compressed sealants in the top channel will not cause glass damage.

\subsection{Stairs}

Stairs are, as a rule, the only available means of egress following an earthquake. Lifts tend to become non-operational. Particular care must therefore be taken to prevent failure of stairs and avoid hazards due to stair enclosures. Stairs tend to act as diagonal struts and examples of damage at the junction of flights can be readily found in the literature e.g. Fig. 21 from the Managua earthquake. In the direction parallel to the landing the flights act as inclinded diaphragms and although somewhat more flexible than along the flights freedom for movement in this direction should in general also be provided.

Fig. 22 shows a stair that features a split landing under construction. One end of each flight is rigidly built into a storey. The ends of the flight at the landing are supported by hangers. In this manner, through the flexibility of the supports and the separation at the landing interstorey, drift may take place in any direction without inducing damaging load into the stairs.

Alternatively where a beam is available at the landing a sliding support may be arranged there instead of hangers. (Fig. 23). The stair flight beams in this instance were precast. Precast treads and landings were erected and fixed to the flight beams. The landing, already in position is rigidly fixed to only one flight to allow relative movement between flights.

Separation gaps in the landings are readily bridged by metal plates. Care must be taken these plates are capable of movements in all directions, including that parallel to the gap otherwise damage will result to any construction that prevents free movement. Similar care must be taken that landing slab separations are not crossed by rigid conduits for stair lights or fire detectors.

\subsection{Partition Walls}

The details employed for separating removable or precast partition systems usually follow the principle of the exterior wall details given in section 7.1. In so far as no weathering is required details are simpler but because provision for horizontal clearances must be made at all intersections of partitions, separation at a considerable number of locations is involved.

Walls with a fire rating present the additional problem that voids at locations provided for relative movement between vertical edges must be bridged in a manner compatible with fire protection. Few space filling materials have both a fire rating and are at the same time highly compressible without high load transfer. Fibreglass may be suitable but the writer is not aware of whether adequate fire tests have been carried out. Fig. 24 shows a detail that is in use in Japan. "Siporex" (a type of foamed autoclaved concrete) panels have their top edges laterally supported in channels which are protected by siporex glued to it by a fire resistant glue. The space at wall ends is filled with fibreglass. At the bottom edges panels are slipped over metal T's fixed to the floor slab. Other details are given in ref (1) but refer to comments below.

The separation of rigid partitions is particularly difficult. In section 4.0 reference has already been made to the danger to the structure in case rigid partitions, which in themselves may be quite weak, act as shear walls. An added reason is that partitions cantilevered or otherwise rigidly joined to the supporting beams will greatly increase the stiffness of the frames containing these beams regardless of whether the partitions are separated from columns and upper storey. Rigid partitions should therefore not be incorporated into ductile frame buildings except where expected deformations are very small. In those shear wall buildings where it is not practical to use the partition as part of the structural system but where the total deformations are likely to be small the details shown in Figs. 25 - 27 may be used. The details provide for horizontal support for partitions of reinforced masonry at the floor lines while at the same time giving moderate freedom to movement between floors in the direction of the partition. In Fig. 25 the vertical reinforcement is terminated in oval shaped sleeves built into the upper storey, and in Fig. 26 the same effect is achieved by the use of dovetail shaped mild steel flats, free to move in a wedge shaped metal channel built into the upper storey. In all cases grouting of the block work walls is difficult if they are constructed following completion of the structure. In some instances it is possible to leave grouting holes in the upper floor and in others the partition may be offset to one side of the beams to allow grouting. Fig. 27 shows a detail that allows relative movement of the floors by flexing of the reinforcement or dowels.

The dimensioning of the dowels and the length of the clear space is governed by the required strength that the dowels must 
have to support the walls horizontally against face loads while at the same time giving sufficient flexibility for building deformations in the plane of the walls. The detail shown allows the wall to be built after completion of the structure. The dowels which are built into the upper floor are left projecting downwards. Dowels need not match the position of the wall reinforcement provided this is considered in the design. Where it is necessary to prevent the transmission of vertical loads through dowels or built in reinforcement, dowels or reinforcement must be greased or taped at their ends and capped with plastic devices that allow vertical movements i.e. the type of cap that is made for use on legs of metal chairs. Fig. 28 shows that joint fillers must be carefully selected as some are capable of transmitting large forces.

In general it will be better to avoid separated masonry partitions. Instead they should be made part of the structure and designed and detailed as shear walls. Some loss of usable floor area and flexibility of planning is unavoidable but simplified detailing and better seismic performance are compensating benefits.

\section{Suspended Ceilings}

Discussion of this important subject is beyond the scope of this paper. Damage to suspended "lay in type" ceilings and lighting fixtures are important features of all recent non-structural damage. The cause has been by too much freedom for movement and not lack of separation of components - the subject of this paper.

\subsection{Specification Provisions and Supervision}

Even more so than with other aspects of structural design, success in achieving the desired results in damage control depends on the closest co-operation between all concerned. Architect and builder must have a clear understanding of the structural designer's intention. To achieve this, N.Z. Ministry of Works and Development have made it a recent practice to include notes with their contract documents explaining separation provisions. An example of this is given in the Appendix. Another aspect often overlooked is loss of separation distance due to normal construction tolerances.

Some damage sustained at Massey University highlights the problem and confirms our experience that once seismic separations are provided movements tend to concentrate in these locations and take place in small earthquakes. Damage was sustained by architectural bridging materials across seismic gaps. The buildings in question (Fig. 7) had metal floor plates across seismic breaks in the corridors linking them. These floor plates were shown by the architect and detailed for sliding transversely across the gap. It was not made clear on the drawings that sliding could also occur parallel to the gap, and as built, low concrete upstands under the corridor walls prevented this. The upstands were sheared off.

Lesson 1: The architect and draughtsmen must understand the problem.

Vertical seismic breaks between the buildings were bridged with PVC water stop type draft stops and metal flashings. The ends of the PVC were torn from rebates in concrete panels not readily accessible into which they were built.

Lesson 2: Bridging materials must be readily replaceable by providing easy access. Common (hindsight) sense, but how often is it done?

Ground filoor vestibule glazing walls were intended to be separated from the floor above by metal channels designed to allow free in-plane movement. The builder however blocked out the corners of metal channels preventing movement and resulting in broken plate glass.

Lesson 3: Builder and site supervisor must understand the nature of the problem.

\subsection{CODE AND INSURANCE REQUIREMENTS}

Suitably formulated code and insurance requirements will encourage damage control features in buildings. In New Zealand earthquake and disaster insurance is carried out by a commission under the Earthquake and War Damage Act, 1944 as a compulsory additional levy upon fire insurance and covers direct losses only. In practice the premium charged does not reflect earthquake risk. Whatever the pros and cons of the provisions of the Act encouraging damage control features.

It is more than 40 years since an important population centre in New Zealand suffered a severe earthquake and not surprisingly few private buildings in New Zealand incorporate damage control features of a greater effectiveness than the absolute minimum required by the present code. But in the light of current knowledge the provisions in this code have a severe deficiency: Separation of components is not required where drifts at code loading is less than $1 / 4 \%$ of the height. Most private buildings are designed to meet this stiffness criterion and thus incorporate no damage control measures. The inadequacy of this provision has already been discussed in section 5 .

DZ 4203 allows non-separation of elements only when the computed drift does not exceed 0.0006 of the storey height. $(2 \mathrm{~mm}$ for a $3.6 \mathrm{~m}$ storey). This drift must be computed in seismic zone $A$, for class III R.C. buildings for the following loadings: shear walls $2 \times 0.15 \times 1.6=0.48 \mathrm{~g}$, category 1 ductile frames $2.0 \times 0.15=0.30 \mathrm{~g}$. For the level of loading perhaps $7 \frac{1}{2} \%$ and $3 \%$ are appropriate damping values for the two systems and this would then correspond to "Skinner" type motions with $0.48 / 2.75$ $=17 \% \mathrm{~g}$ and $0.30 / 2=15 \% \mathrm{~g}$ max. ground accelerations. i.e. approx. $\frac{1}{2}$ EI Centro N.S.

Some field evidence is available to indicate that this provision is reasonable. Extensive broken glass damage was reported in Shimizu City (Japan) during the April 20, 1965 earthquake (17). Peak accelerations were about $1 / 10 \mathrm{~g}$ and the intense phase of shaking lasted about $15 \mathrm{sec}$. Up to $20 \%$ of fixed windows were broken in several R.C. 
buildings with fundamental periods of 0.3 to $0.6 \mathrm{sec}$. These buildings suffered little or no damage. Displacement spectra for the earthquake allowed interstorey drift to be evaluated to be from 0.0002 to 0.001 of storey height i.e. approx. $1 \mathrm{~mm}$ to $4 \mathrm{~mm}$ for a $3.6 \mathrm{~m}$ storey. The earthquake may be regarded to be about $1 / 3 \mathrm{EI}$ Centro N.S. in "size".

The effect of the separation provision in DZ 4203 will therefore be to exclude all but very stiff structures. This is well justified not only by the economic consequences of damage - to be paid for by Government guaranteed insurance (11) - but also because of the obvious life hazard created by nonstructural damage. The code requires separations to be computed elastically for a specified multiple of the code loading (8). For ductile structures the separations must be computed elastically using approximately 2 to $2 \frac{1}{2}$ times the basic (ultimate) code earthquake loading (see also section 5.3).

The current trend away from owner users towards (speculative) construction by developers for sale to others has further reduced the motivation for building damage control features into structures. Adequate provision in the code has become more necessary than ever. Codes as a rule provide only for minimum measures of control rather than desirable levels and economic encouragement through realistically scaled insurance rates would be helpful. The added cost to the insurers in having to classify buildings including consideration of damage control features would be recovered not through the premiums but from greatly reduced losses in case of an earthquake.

\subsection{ECONOMICS}

In a small country with limited local resources, barely able to cope with normal building activity and with rescue resources geared to deal with little more than a predictable number of daily traffic accidents, damage in a severe earthquake may result in major disruption of the entire infra-structure of the country. These and other aspects have been discussed elsewhere (9) (15) and cannot be ignored. The following comments apply to economics in a very narrow sense only.

Few detailed studies have been made of the economics of modern earthquake resistant design. Reference (12) gives the cost increase due to seismic provisions for non-structural items as a percentage of the total cost of the buildings as $1.4 \%$ for Uniform Building Code seismic zone 3 , and $2.3 \%$ for a fictitious seismic zone $S$ (twice the loading requirements for seismic zone 3 - plus protection of non-structural items). The bulk of the increase in seismic zone $S$ was due to the provision of special window systems and many other precautions including safety wires for suspended lighting fixtures, bracing of transformers, heavier guard rails and more fixings etc. for elevators. The cost increase given for partitions was only $0.2 \%$. From one study of a particular building the author believes that the increase in the case of partitions in New Zealand may be somewhat larger but the total cost increase quoted appears to be of the right order. One reason why cost estimates may vary considerably is that comparisons cannot be made merely on the basis of simple re-design for a particular building. The design for damage control must start at the planning stage and it is then and there that a decisive influence on costs may be exerted.

In simplistic terms the cost of damage control compared to the alternative option of investing a sum of money equal to the cost of damage control to pay for damage when it occurs might be made as follows:

Assume: Return period of damaging earthquakes : 25 years. Cost of damage control features : $2 \%$ of total building cost. Net return in invested sum (following adjustment for inflation): $5 \%$. $0.02 \mathrm{x}$ Building Cost $\times 1.05^{25}=0.07 \times$ Building cost. The actual cost of damage is likely to be far greater than $7 \%$ of the total cost of the building.

\subsection{CONCLUSION}

Modern structures, particularly ductile frames not incorporating deformation limiting devices are subject to large displacements in earthquakes of moderate and greater intensity. The great potential which exists for non-structural damage is evident both from theory and field observations. Hazards may be created to people in and around a building, its intended structural performance altered and high economic losses result.

Choice of structural form and careful detailing will minimise non-structural damage. To be effective, damage control measures call for close co-operation between architect and engineer at the sketch plan stage of a project and must be clearly understood by all involved including those responsible for the building's erection.

\section{ACKNOWLEDGEMENTS}

The permission of the Commissioner of Works to publish this paper is acknowledged. The writer wishes to thank members of the design and drafting staff for their assistance. Special acknowledgement is made to Mr. T. N. Mitchell, District structural Engineer, Ministry of Works and Development, Wellington for his many helpful comments and for making the Appendix available.

\section{REFERENCES}

1. Newmark \& Rosenblueth, Fundamentals of E.Q. Engineering.

2. City of Los Angeles, Proposed Building Code Amendments 1972.

3. Building Research Institute of Japan proposal 1972 .

4. R. I. Skinner, Earthquake Generated Forces and Movements in Tall Buildings, R.I. Skinner, N.Z.D.S.I.R. Bulletin 166 .

5. Newmark \& Hall, Seismic Design Criteria for Nuclear Reactor Facilities, IV WCEE Chile 1969.

6. G. W. Housner, Design Spectrum, Weigel, Earthquake Engineering.

7. DZ 4203 Draft N.Z. Standard Code of Practice for General Structural Design and Design Loadings 1973.

8. R. W. G. Blakeley, A Review of the New 
Code Provisions for Separation of Elements, Bull. N.Z. N.S.E.E., Vol. 7. No. 3. 1974.

9. O. A. Glogau, Design of Public Buildings, Bull. N.Z. N.S.E.E., Vol. 5 , No. 4, Dec. 1972 .

10. S. W. Toomath, Architectural Detailing for E.Q. Movement Bull. N.Z. N.S.E.E., Vol. 1, No. 1. 1968 .

11. N.2. Earthquake and War Damage Regulations 1956, Wellington, Government Printer.

12. S. K. Leslie, Earthquake Code Evolution and the Effect of Seismic Design on the Cost of Buildings M.I.T. Structures Publication No. 341, 1972.

13. A. W. Smith, Some Aspects of Seismic Damage, N.z. Engineering, September 15, 1961 .

14. J. R. Bennet, Earthquake Insurance in New Zealand, Proc. 3 WCEE 1965.

15. O. A. Glogau, Discussion of Paper by G. Grandiori and D. Benedetti ' On the Choice of the Acceptable Seismic Risk". Int. J. Earthq. Struct.. Dyn., vol.
2, 1974 p. 296 .

16. R. W. G. Blakeley, R. C. Cooney and L. M. Megget. Seismic Shear Loading at Flexural Capacity in Cantilever Shear Wall Structures. South Pacific Regional Conference on E.E. Wgtn 1975 .

17. Y. Osawa et al. On the damage of Glass in R.C. Buildings. Bull. of the (Japan) E.Q. Research Inst., Vol. 43, 1965.

\section{CREDITS}

Fig. I M. Fintel, Quake Lesson from Managua, Civil Engineering ASCE Aug. 1973.

Fig. 2 K. Steinbrugge, J. Manning, H. Degenkolb, Building Damage in Anchorage. The Prince William Sound, Alaska E.Q. 1964, U.S. Dept. of Com.

Fig. 3 Managua, Nicaragua Earthquake of 23 Dec. 1972.

Fig. 4 R. I. Skinner, DSIR Bulletin 19I, New Zealand.

TABLE 1.

\begin{tabular}{|c|c|c|c|c|c|}
\hline \multirow[t]{2}{*}{$\begin{array}{l}\text { Structure } \\
\text { Period }\end{array}$} & \multirow[t]{2}{*}{$\frac{v}{w_{t}}$} & \multirow[t]{2}{*}{$\begin{array}{l}\text { Damping } \\
\text { coeff. }\end{array}$} & \multirow[t]{2}{*}{$\begin{array}{l}\text { Amplif. } \\
\text { factor }\end{array}$} & \multicolumn{2}{|c|}{$\begin{array}{l}\text { Max. ground acceleration } \\
\text { \& g for no damage }\end{array}$} \\
\hline & & & & $\begin{array}{l}\text { Separation } \\
\frac{1}{2} \mathrm{DZ} 4203\end{array}$ & $\begin{array}{l}\text { Separation } \\
\text { requirement } \\
\text { according to } \\
\text { DZ } 4203\end{array}$ \\
\hline & & & & 1 & 2 \\
\hline 0.3 & 0.15 & $\begin{array}{r}2 \\
5 \\
10\end{array}$ & $\begin{array}{l}3.2 \\
2.3 \\
1.8\end{array}$ & $\begin{array}{l}4 \cdot 5 \\
6 \cdot 5 \\
8\end{array}$ & $\begin{array}{l}9 \\
13 \\
16.5\end{array}$ \\
\hline 1.0 & 0.125 & $\begin{array}{r}2 \\
5 \\
10\end{array}$ & $\begin{array}{l}1.25 \\
1.0 \\
0.9\end{array}$ & $\begin{array}{l}10 \\
12.5 \\
14\end{array}$ & $\begin{array}{l}20 \\
25 \\
27.5\end{array}$ \\
\hline 2.0 & 0.072 & $\begin{array}{r}2 \\
5 \\
10\end{array}$ & $\begin{array}{l}0.6 \\
0.5 \\
0.45\end{array}$ & $\begin{array}{l}12.5 \\
15 \\
16.6\end{array}$ & $\begin{array}{l}25 \\
30 \\
33\end{array}$ \\
\hline
\end{tabular}




\section{APPENDIX \\ EXAMPLE OF SPECIFICATION NOTES \\ SEISMIC DESIGN PRINCIPLES}

The structural system employed in this building is a concrete frame of columns, beams and floor slabs which resists all forces, and particularly horizontal earthquake forces, without the use of any walls. When subject to horizontal earthquake forces the concrete frame will move significantly and all elements within the frame are detailed to allow for this movement.

The understanding of the nature of this movement and the way with which it has been dealt in detailing is essential to the correct construction of this work. Any detail not shown will have to be solved with this understanding and consistent with detailing which is shown.

Under earthquake forces each floor will have a relative movement to the floor above and below in any direction. Certain magnitudes of movement have been allowed for in the details as below -

Relative Movement Plus or Minus

Main Six Storey Block to Single Storey Blocks at roof level of Single storey Block

Main Six Storey Block

Ground Floor to First Floor

Ground Floor to Clerestorey Beam

Clerestorey Beam to First Floor

First Floor to second, second to Third,

Fourth Floor to Concrete Roof Beams

Single Storey Blocks

Ground Floor to Roof

$\frac{1}{2} "$

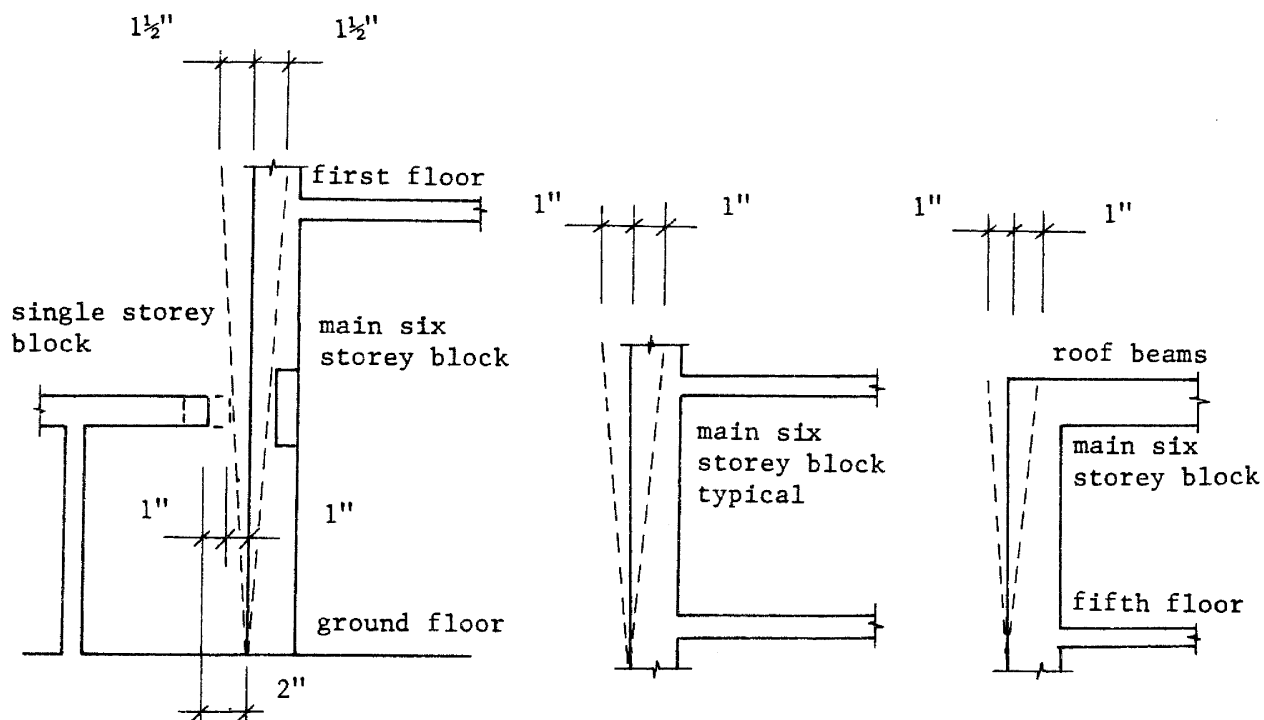




\section{SPECIFIC CASES}

The following general principles apply -

Between Blocks :

Between the Main Six Storey Block and the Single Storey Blocks, the timber wall dividing the Mail Room from the Postal area is separated 2" from the Main Block Columns, and is not fixed in any way to them.

\section{WINDOWS GROUND FLOOR :}

(a) Windows on Floor. The sills are fixed to the floor. The heads are attached to concrete beams (or, in the case of Front Entry, to framing) in such a way as to allow the windows to rock in and out when structure above moves perpendicular to plane of windows, and in such a way that the windows remain stationary relative to the floor and slide relative to structure above when it moves parallel to the plane of the windows. Note special cases around stair enclosures, see Details.

(b) Windows above clerestorey beams. Sills are fixed as above. Heads are attached to slab soffit to allow movement as above.

\section{WINDOWS FIRST TO FOURTH FLOORS :}

These comprise upper and lower windows. The upper windows are fixed at the heads to the slab above. The sills are braced back to the slabs above so that they are fixed in all directions relative to the slabs above.

The lower windows are fixed at the sills.

The heads of the lower windows are attached to the sills of the upper windows to allow for movement in the same way as described for the ground floor windows.

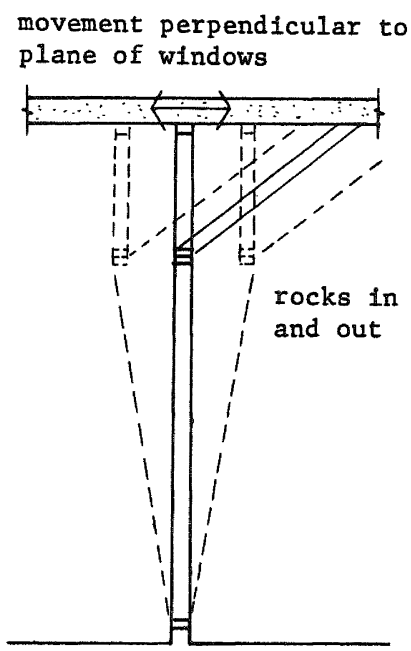

movement parallel to plane of windows

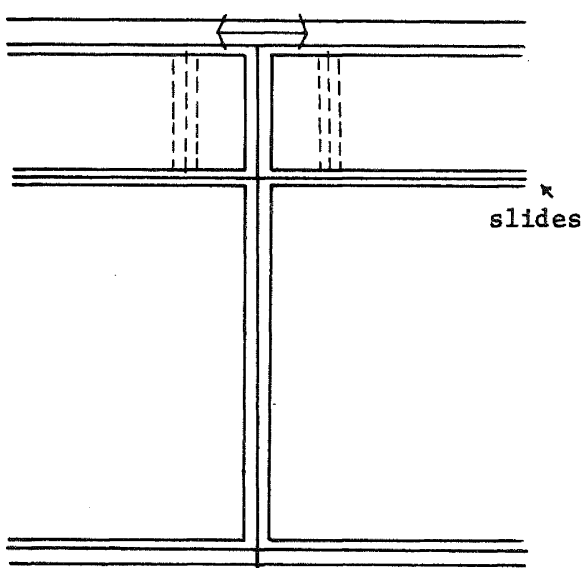

typical window

\section{FIFTH FLOOR :}

All walls, partitions and roof/ceiling are fixed relative to the floor. Movement is allowed at each column. The roof/ceiling element hangs from the beams above, is a rigid plane and maintains the tops of the partition in their correct relationship.

The external wall elements are cantilevered off the floor, are rigid in all directions, and are fixed to the roof/ceiling element to maintain it in its relation to the floor.

\section{FIRST TO FOURTH FLOORS - PARTITIONS AND CEILINGS :}

The partitions and ceilings are fixed relative to the floor. The ceilings are suspended from the slabs above by flexible hangers, they are rigid planes and are maintained in their fixed relation to the floor by the partitions which are rigid planes. The ceilings, partitions and floors therefore form rigid boxes. Where partitions or ceilings abut columns allowance is made for movement in all directions. Where they abut external windows, allowance is made for the rocking in and out movement of the windows. 


\section{2}

WALLS AROUND STAIRS AND LIFTS :

These are divided in their height, at the same line as the upper and lower windows, to form one rigid box fixed to the floor and one rigid box fixed to the slab above. Each box slides in any direction relative to the other.

WALLS AROUND TOILETS FIRST TO FIFTH FLOORS :

These are rigid boxes fixed to the floors.

EXTERNAL CONCRETE WALLS IN SINGLE STOREY BLOCKS :

These are designed with dowel connection to columns and beams, allowing rocking in and out with movement perpendicular to their plane, and allowing the walls to remain fixed relative to the floor with movement parallel to their plane.

INTERIOR CONCRETE WALLS IN SINGLE STOREY BLOCKS :

These are designed as rigid boxes dowelled to external walls to allow the external walls to rock as described above and allowing movement in all directions relative to ribs or beams above.

\section{PARTITIONS IN SINGLE STOREY BLOCKS :}

These are built as rigid boxes fixed to the floor, extending to the rib and beam soffit level, where they abut either ribs, beams or stub partitions fixed in relation to the roof structure. The partitions generally are free to move in all directions where they abut ribs, beams or stub partitions, but this is modified where the partition is over 12 feet in length by dowelling the top of it to the rib or beam soffit or bottom of stub partition to allow the centre of the partition to deflect with the structure above. 


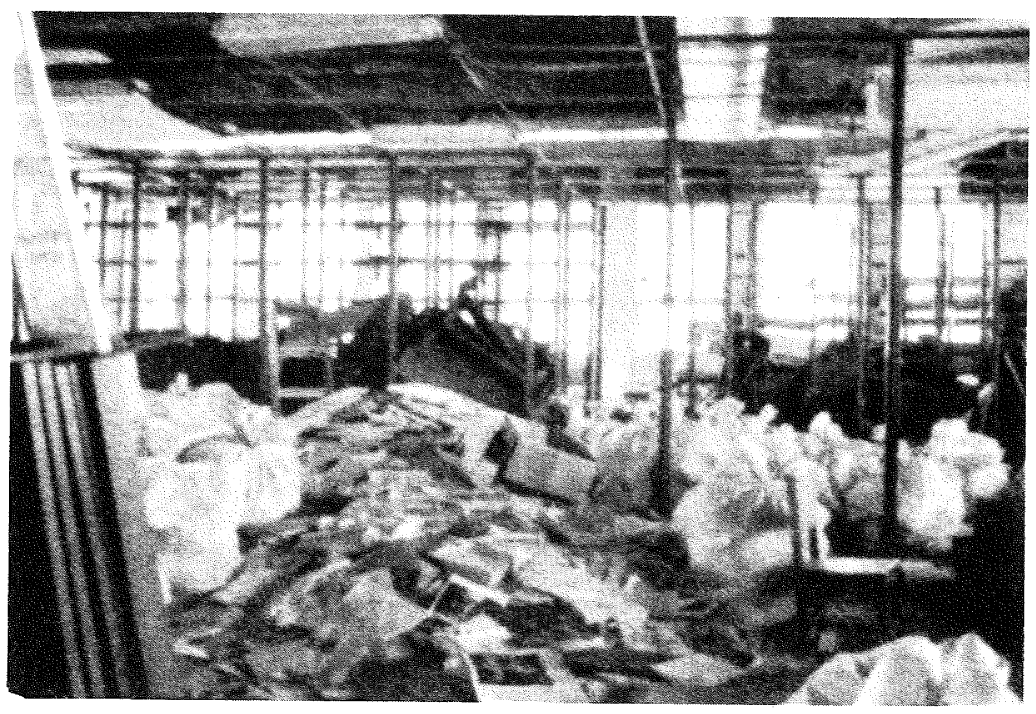

FIGURE 1: BANCO CENTRAL, MANAGUA 1972: WAS DESIGNED FOR LOADINGS CONSIDERABLY IN EXCESS OF 1961 SEAOC CODE
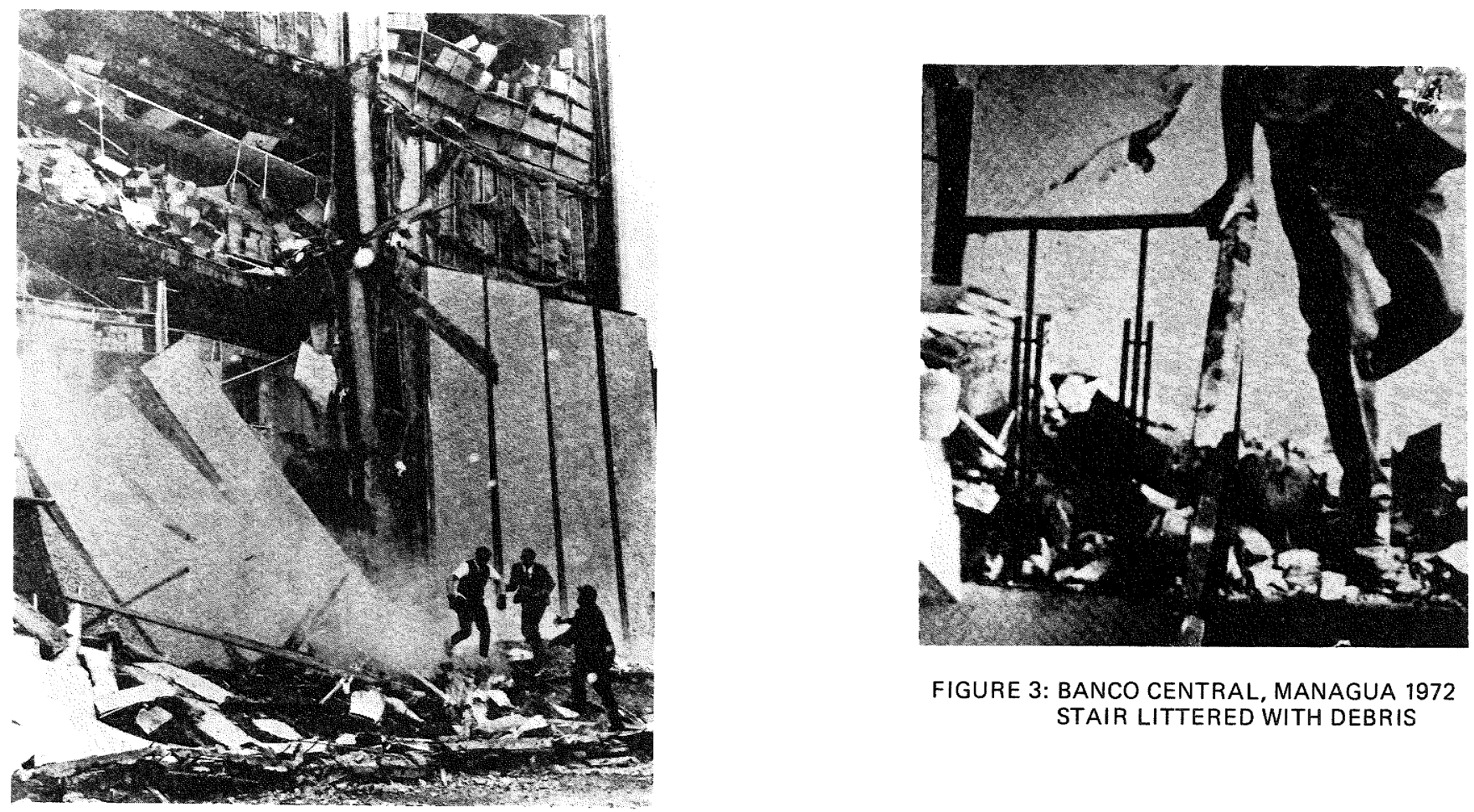

FIGURE 3: BANCO CENTRAL, MANAGUA 1972 STAIR LITTERED WITH DEBRIS

FIGURE 2: PENNY BUILDING, ALASKA 1964
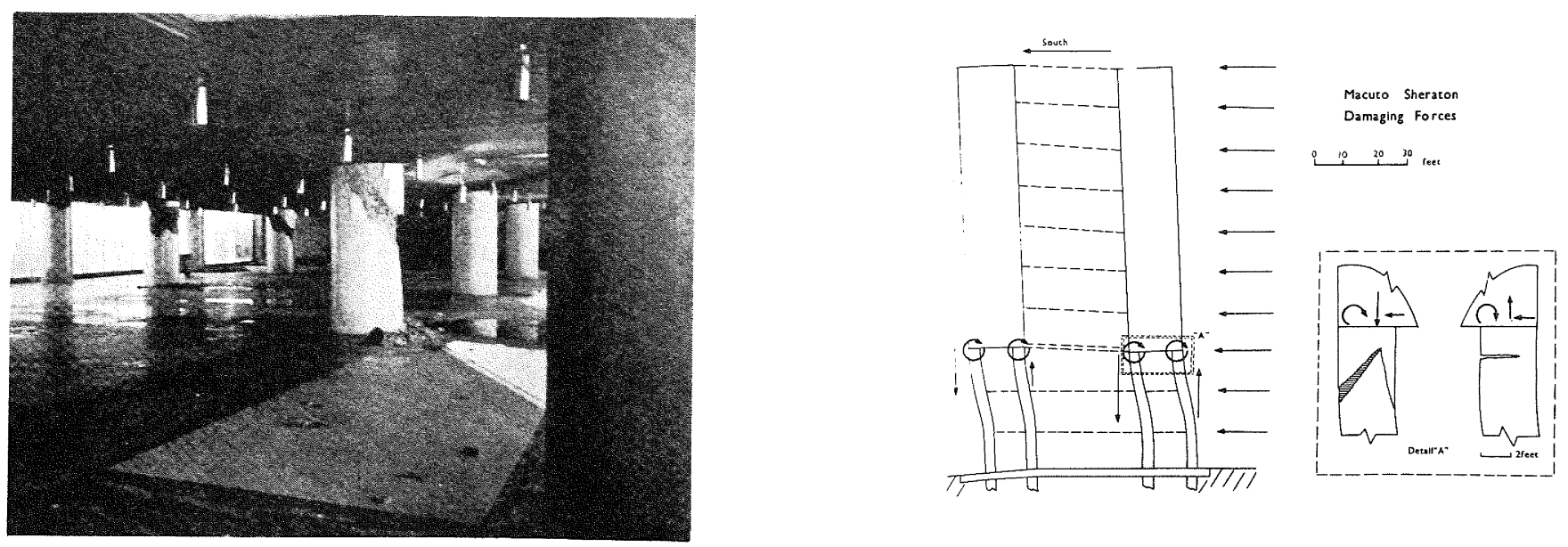

FIGURE 4: MACUTO SHERATON, CARACAS 1967: SERIOUS STRUCTURAL DAMAGE. DUE TO NON STRUCTURAL UPPER STOREY IN FILLING PANELS 


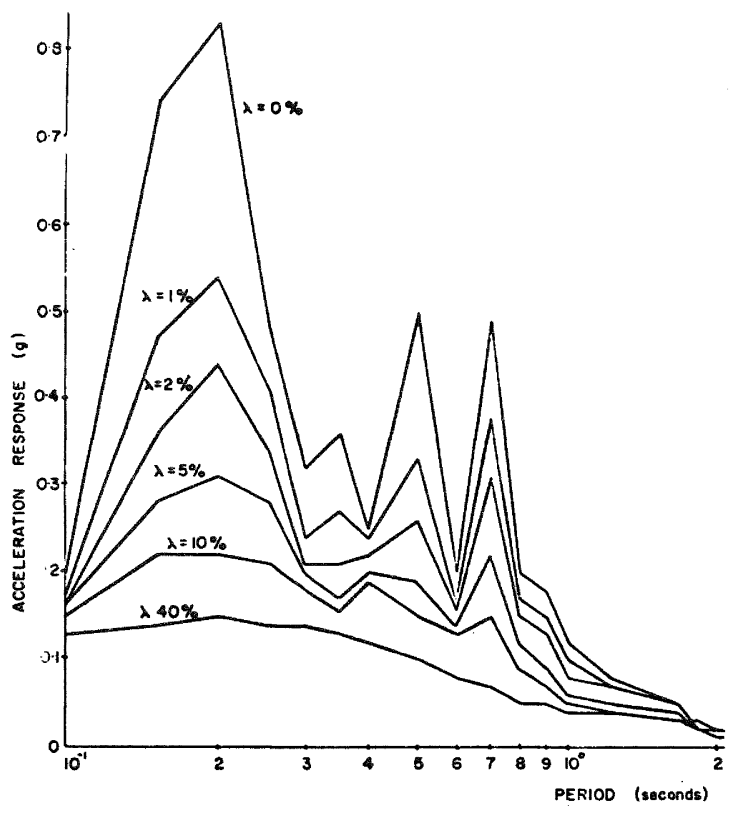

FIGURE 5a: MASSEY UNIVERSITY 6 JANUARY, 1973 HORIZONTAL COMPONENT N $15^{\circ} \mathrm{E}$

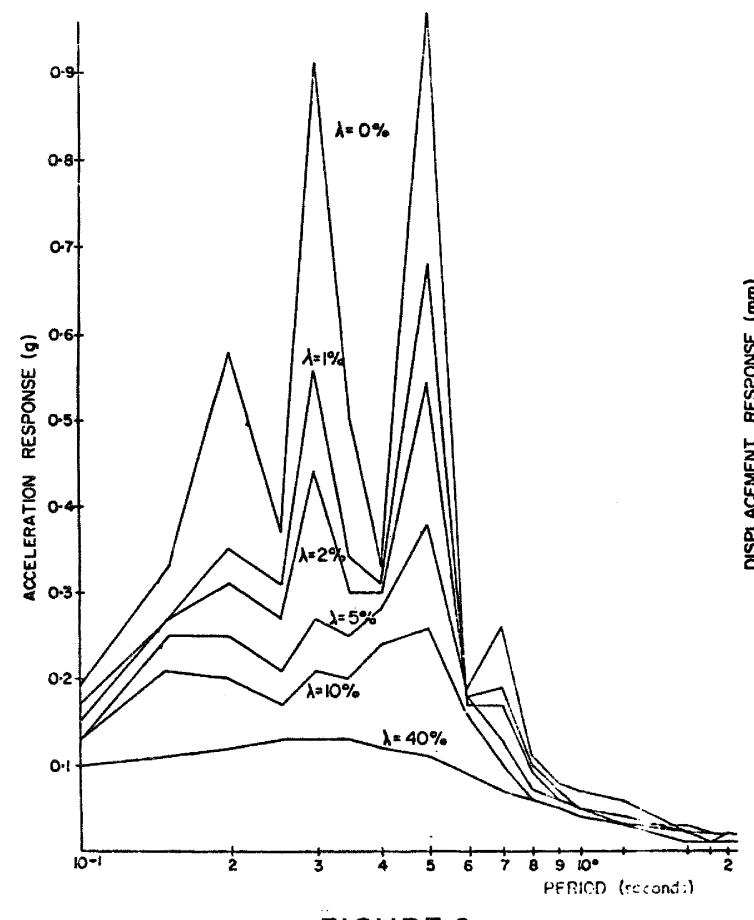

FIGURE 6a:

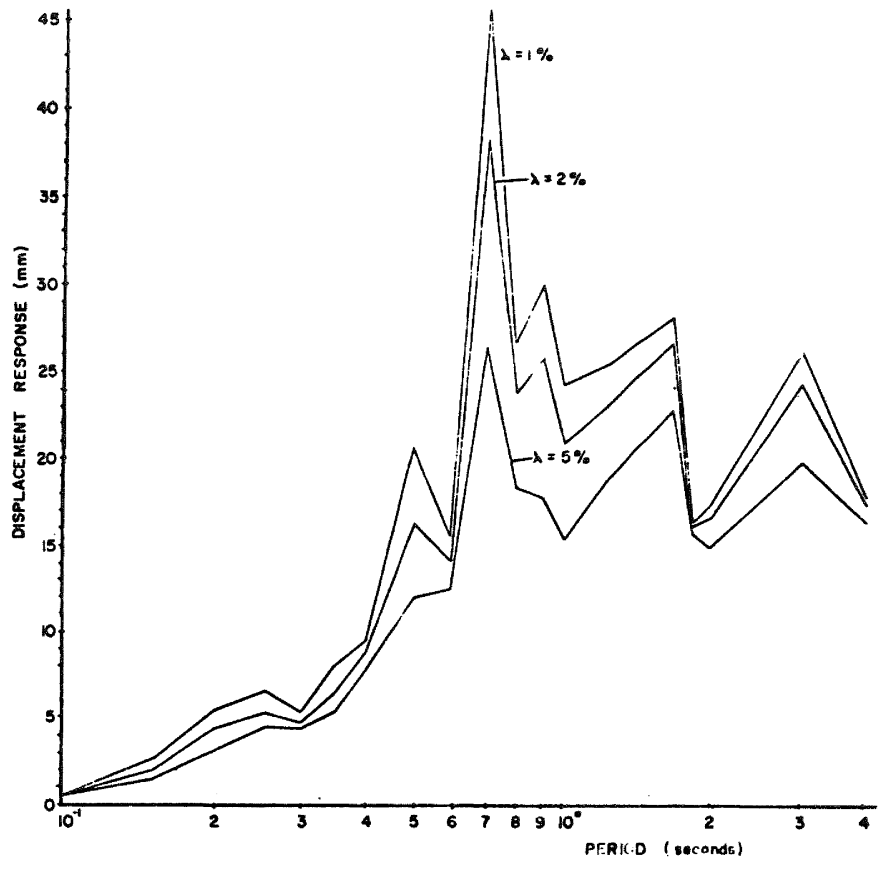

FIGURE 5b:

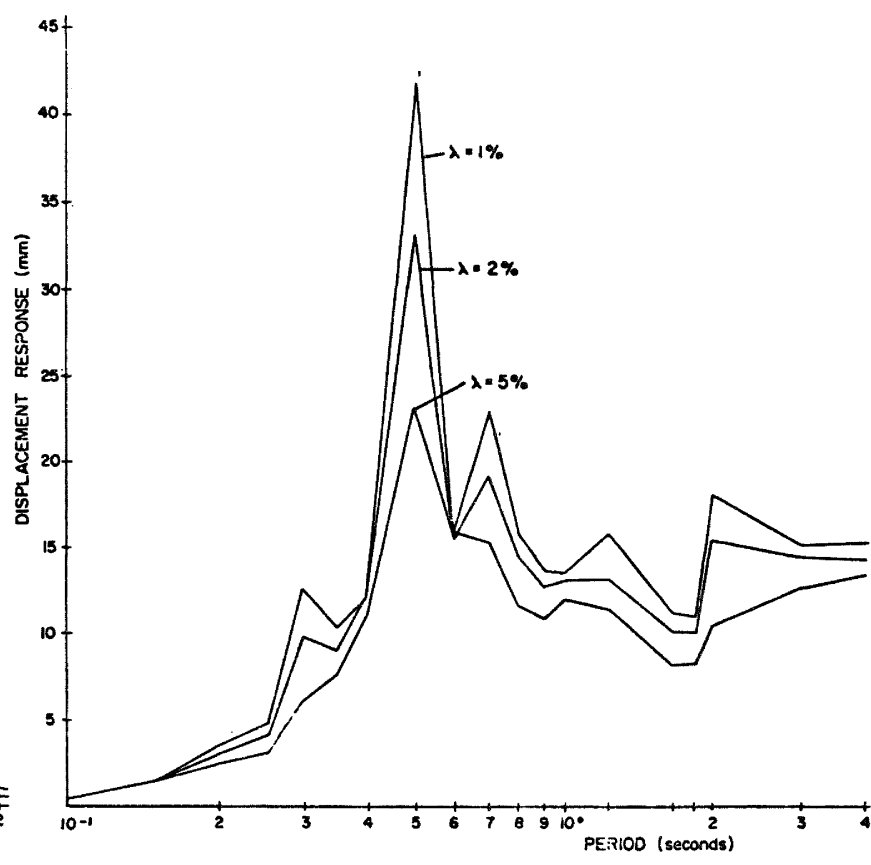

FIGURE 6b:

MASSEY UNIVERSITY 6 JANUARY, 1973 HORIZONTAL COMPONENT N235 E
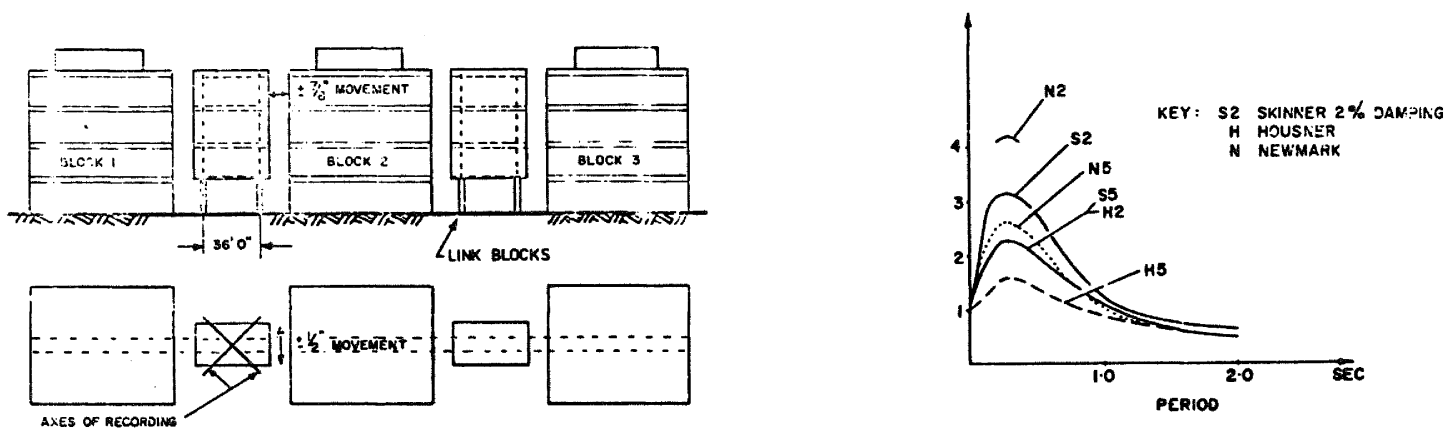

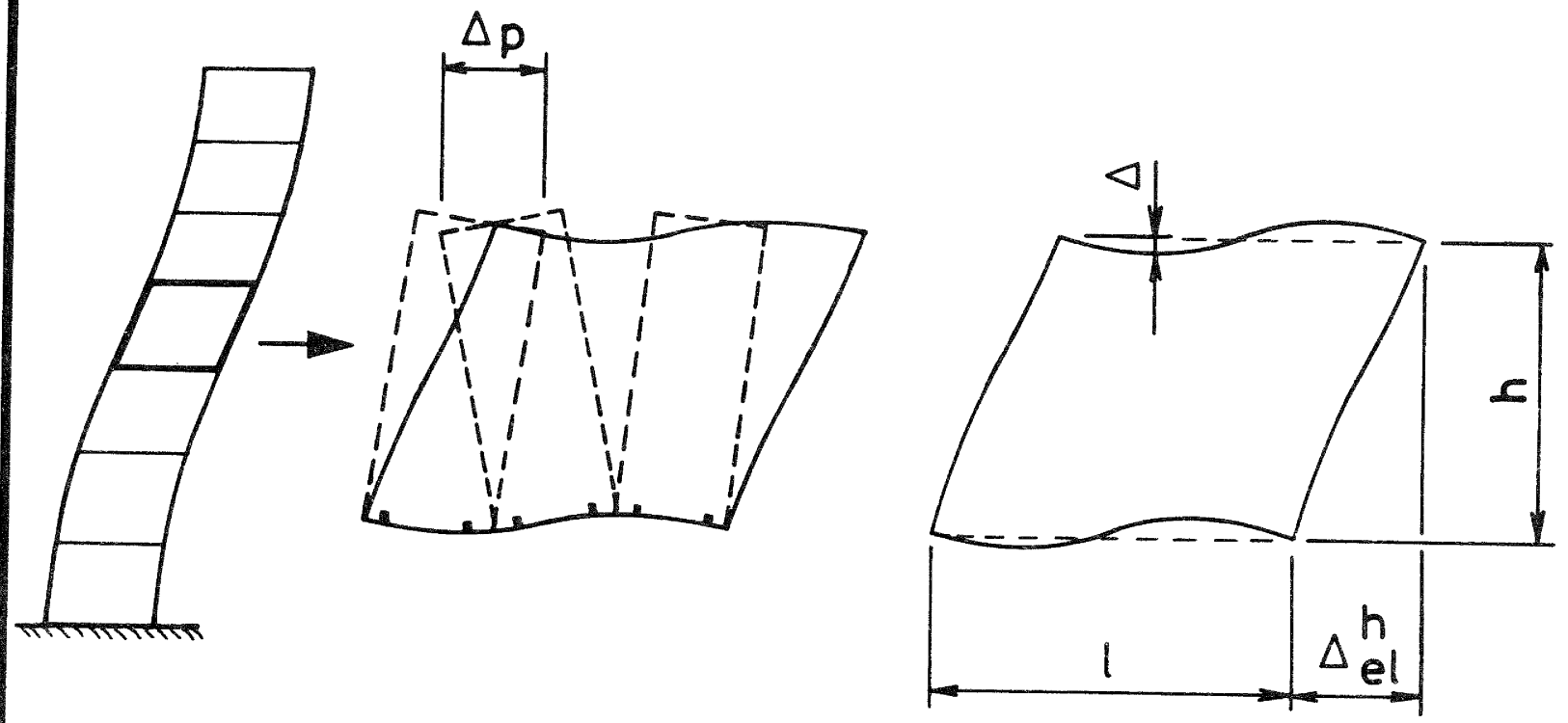

FIGURE 9 : DEFORMATION OF A DUCTILE FRAME
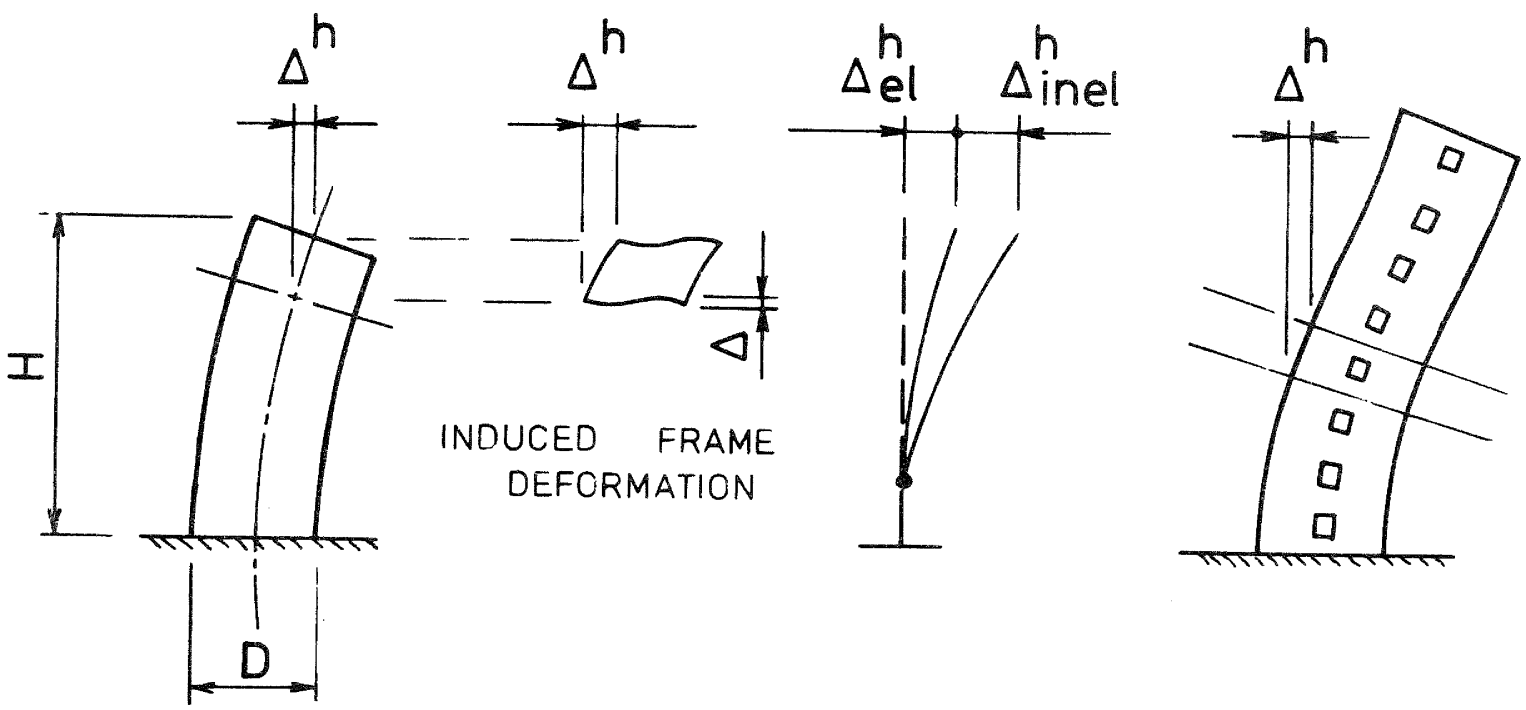

(a) CANTILEVER SHEAR WALL

(b) COUPLED JHEAR WALL 


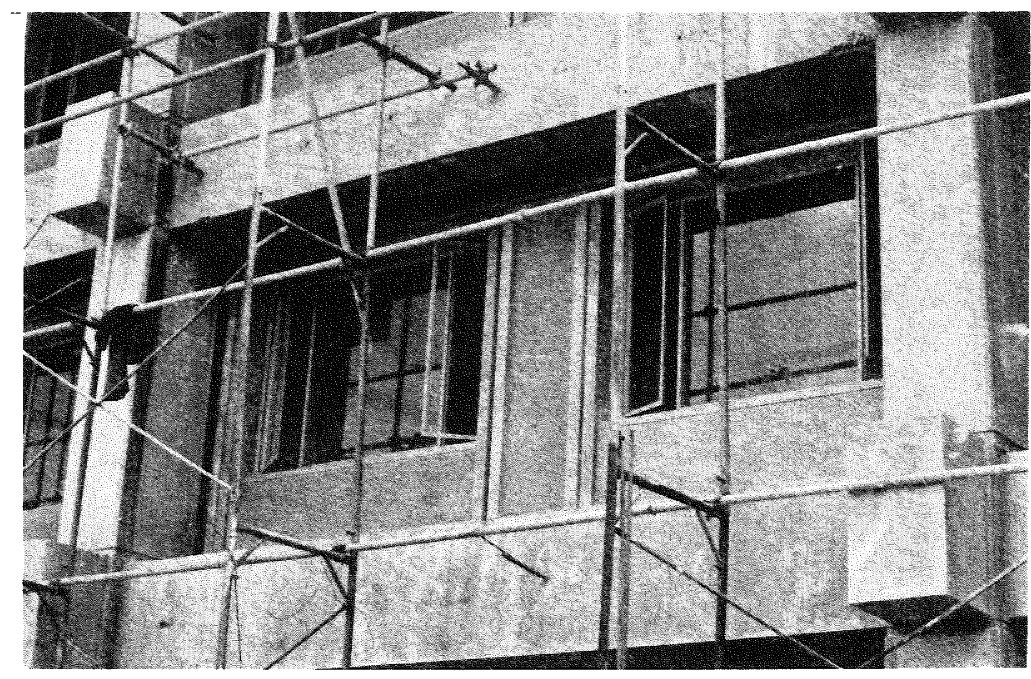

FIGURE 11: EXTERIOR CLADDING ELEMENTS ARE POSITIONED INSIDE EXTERNAL FRAME RESULTING IN SIMPLER AND MORE EFFECTIVE SEPARATION DETAILS

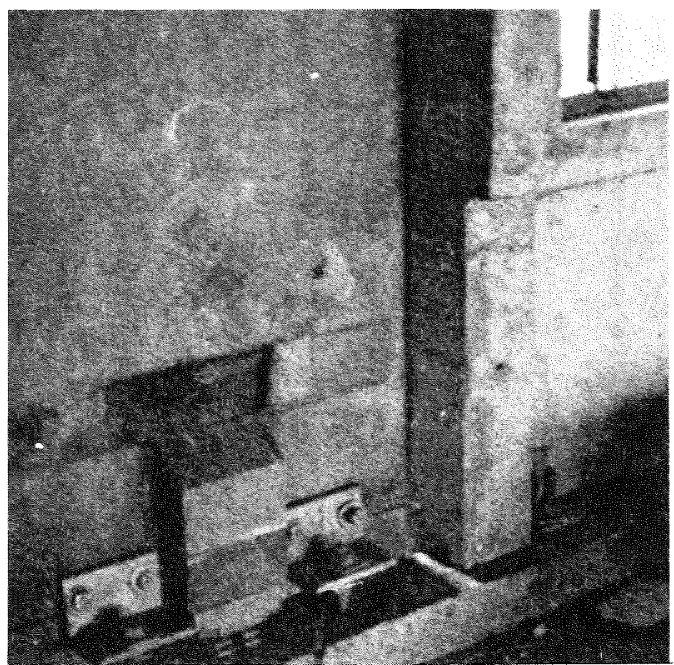

FIGURE 13: PANEL SUPPORT PRIOR TO MORTAR PACKING
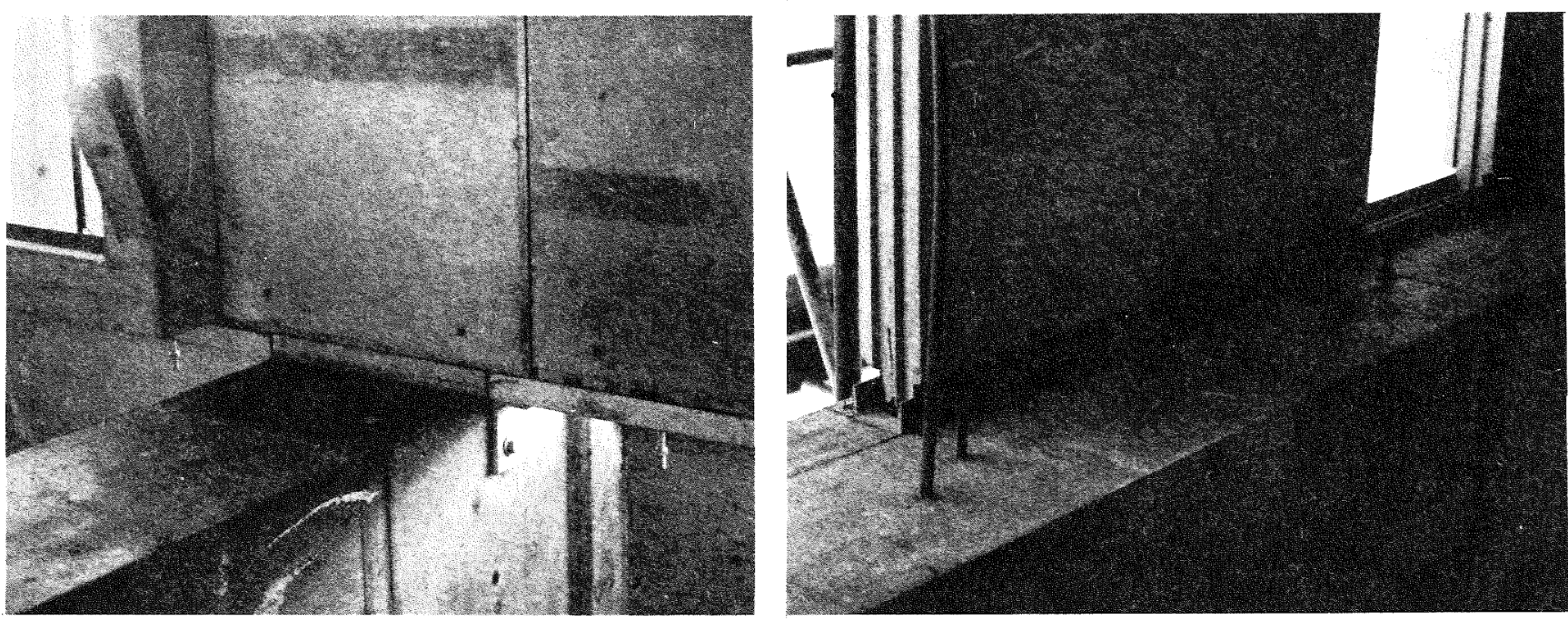

FIGURE 12 \& 14: CLADDING DETAILS ARE FREE TO SLIDE IN CHANNEL
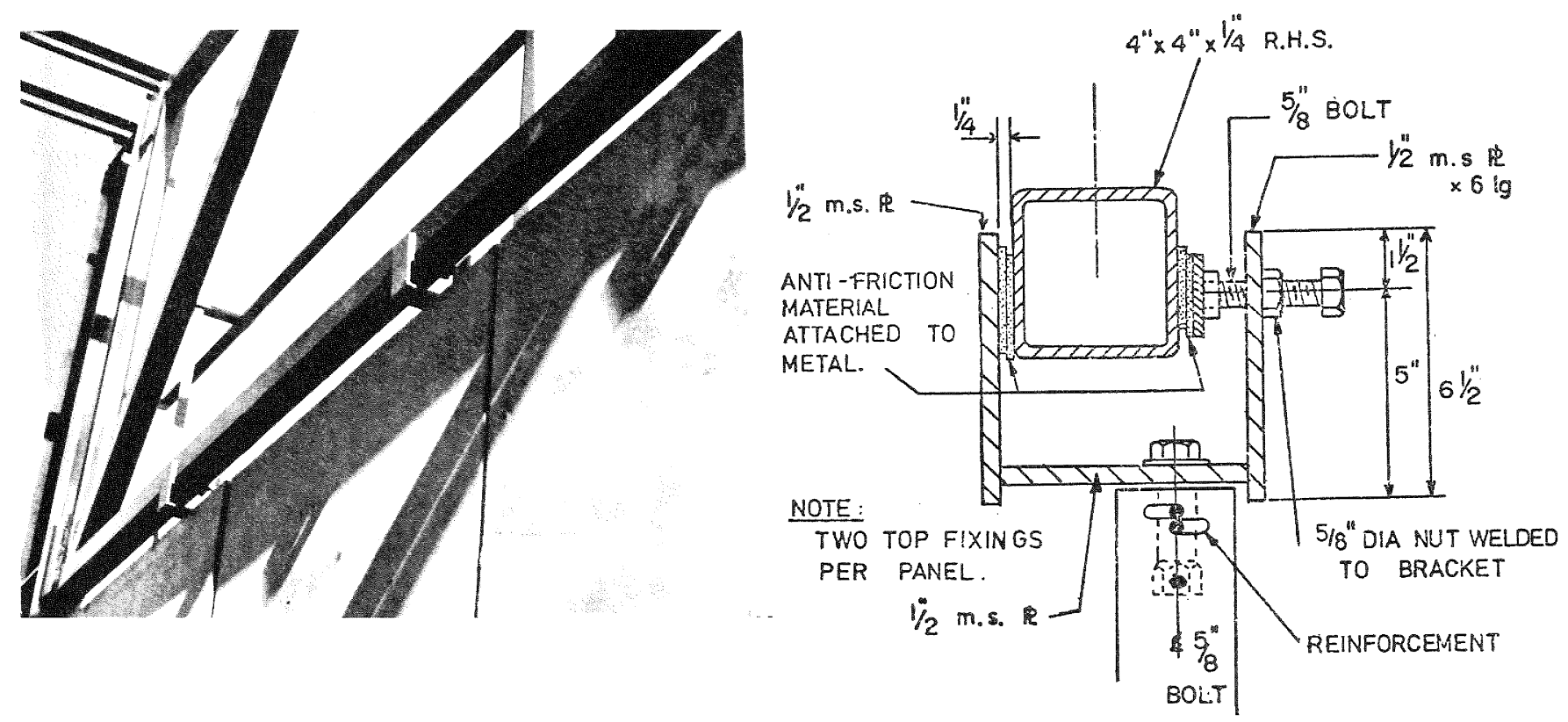

FIGURE 15 \& 16: PANEL SUPPORT FOR LIGHT INDUSTRIAL BUILDING. SECOND BRACKET NOT YET FIXED 


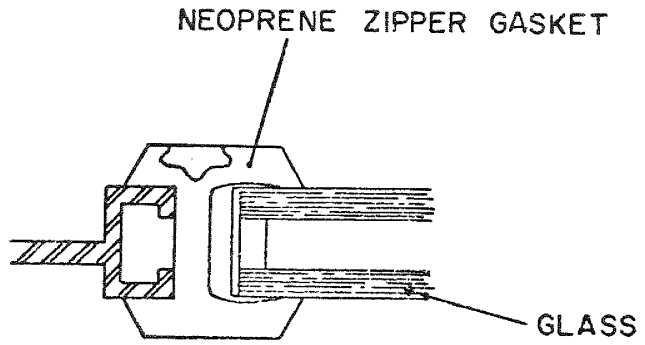

FIGURE 17: SEISMIC WINDOW GASKET

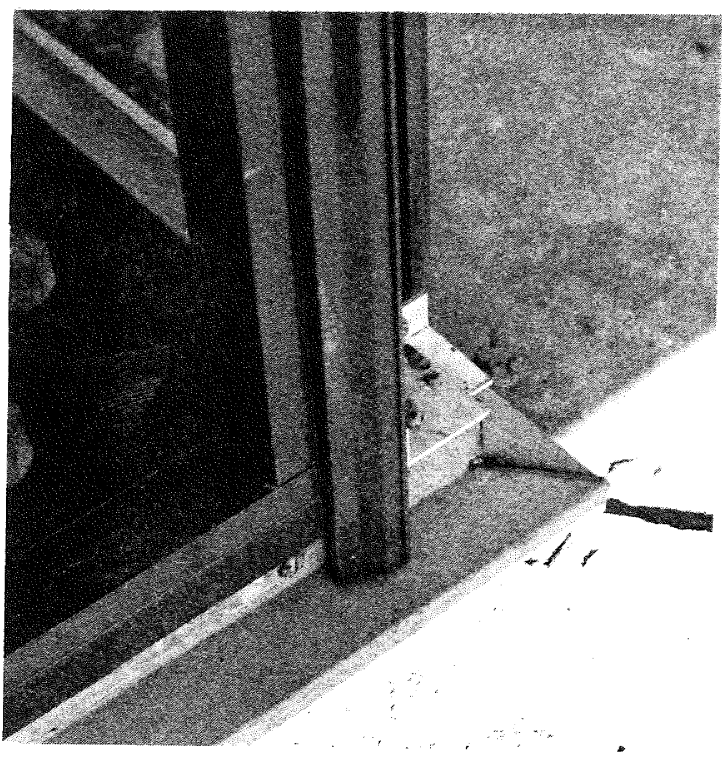

FIGURE 19

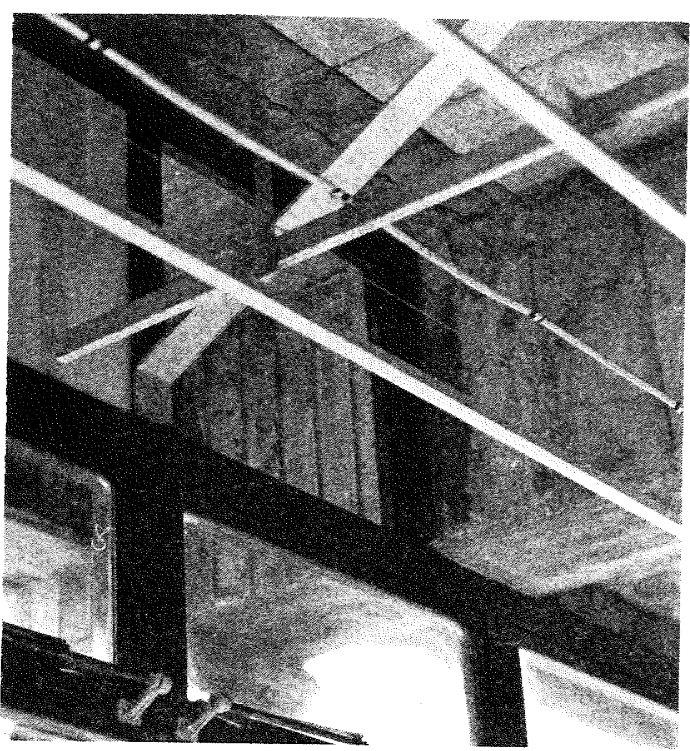

FIGURE 18

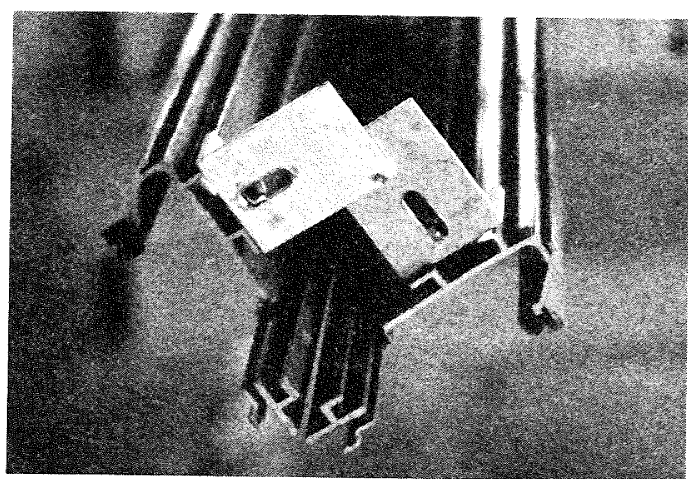

FIGURE 20

FIGURES 18-20: METAL CURTIAN WALL DESIGNED FOR MOVEMENT

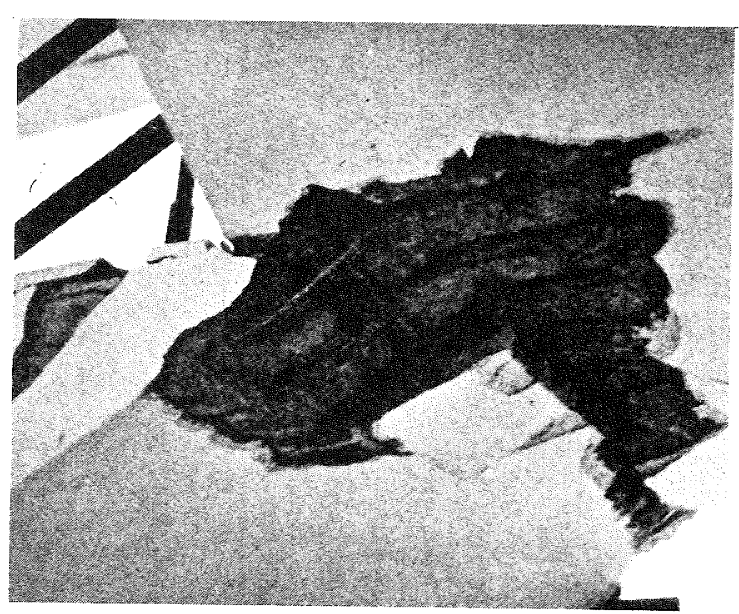

FIGURE 21: STAIR DAMAGE, MANAGUA 1972

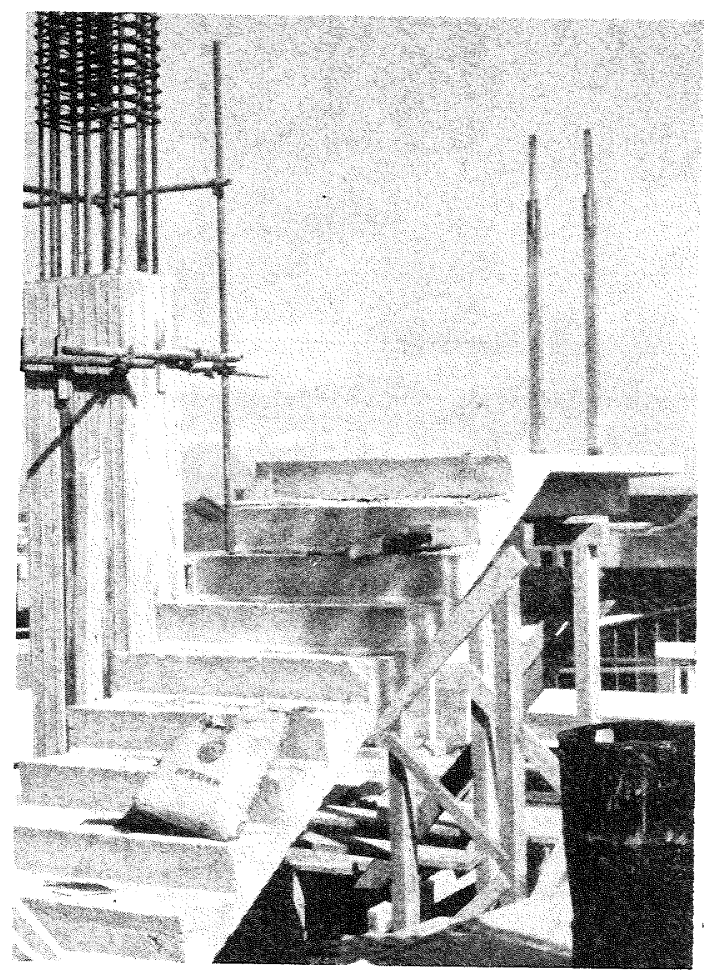

FIGURE 22: STAIR FEATURING SPLIT LANDING TO BE HUNG FROM UPPER STOREY 


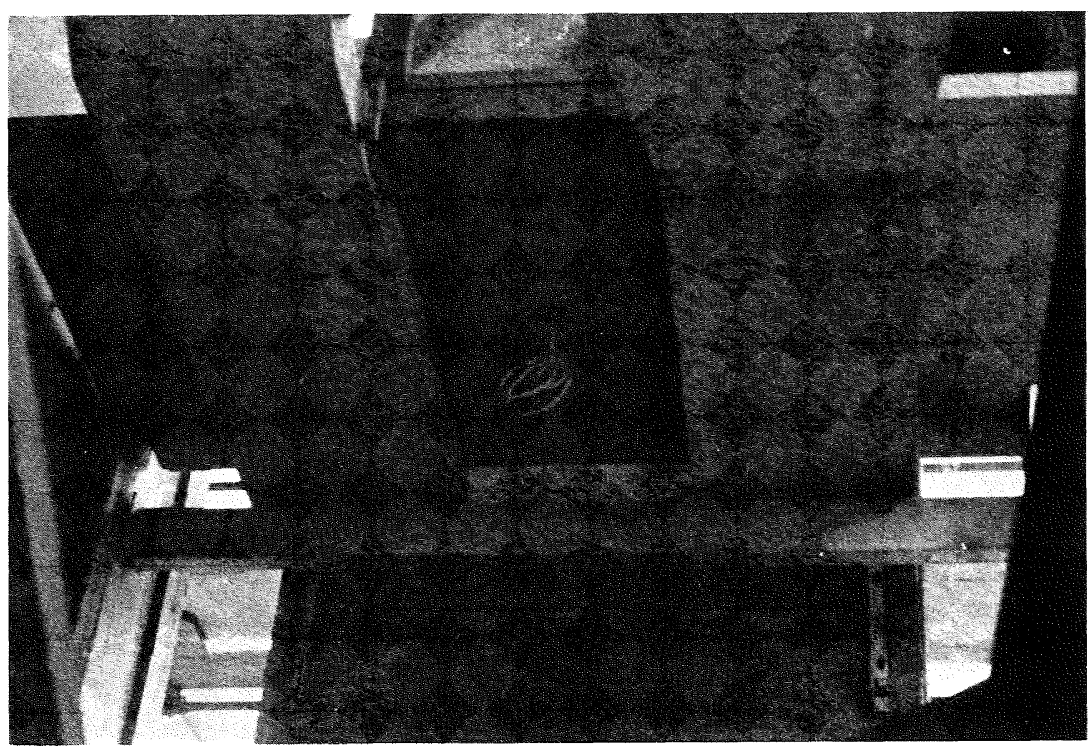

FIGURE 23: PRECAST STAIR DESIGNED TO ALLOW FOR DRIFT

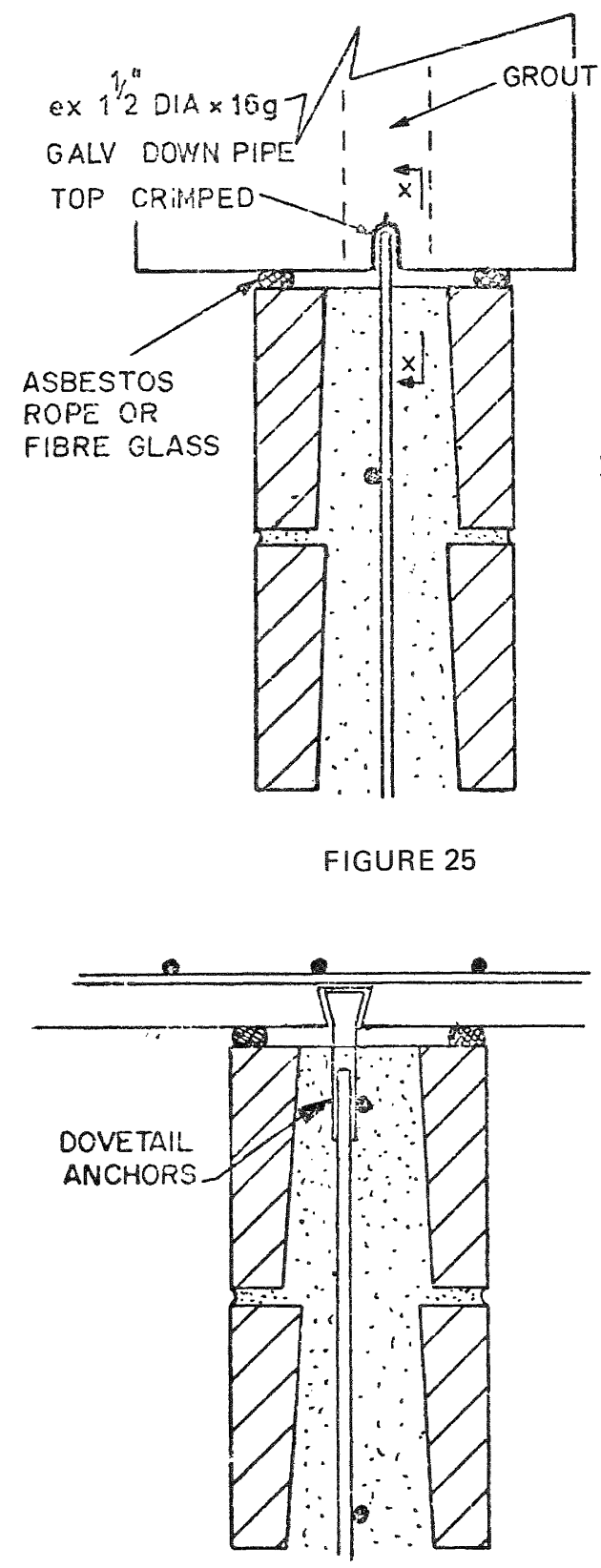

FIGURE 26

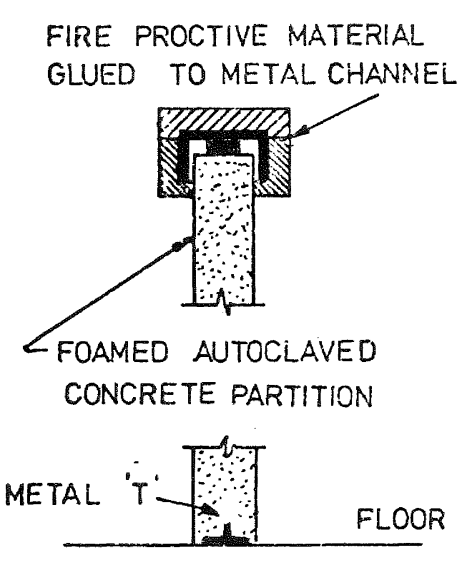

FIGURE 24: PARTITION WITH FIRE RATING DESIGNED FOR DRIFT

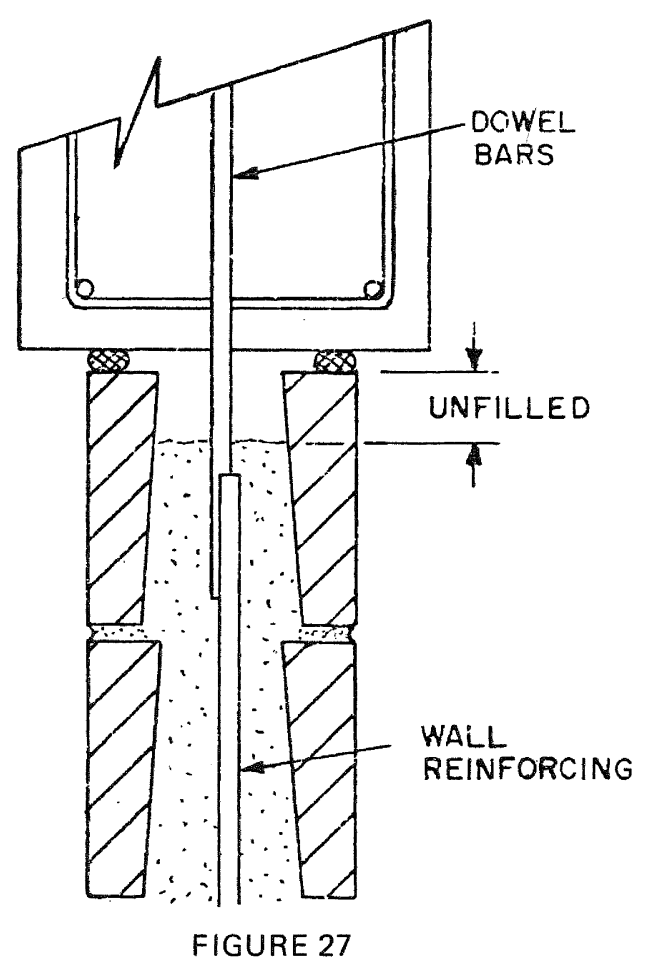

FIGURES 25-27: MASONRY PARTITIONS ALLOWING MODERATE DRIFT

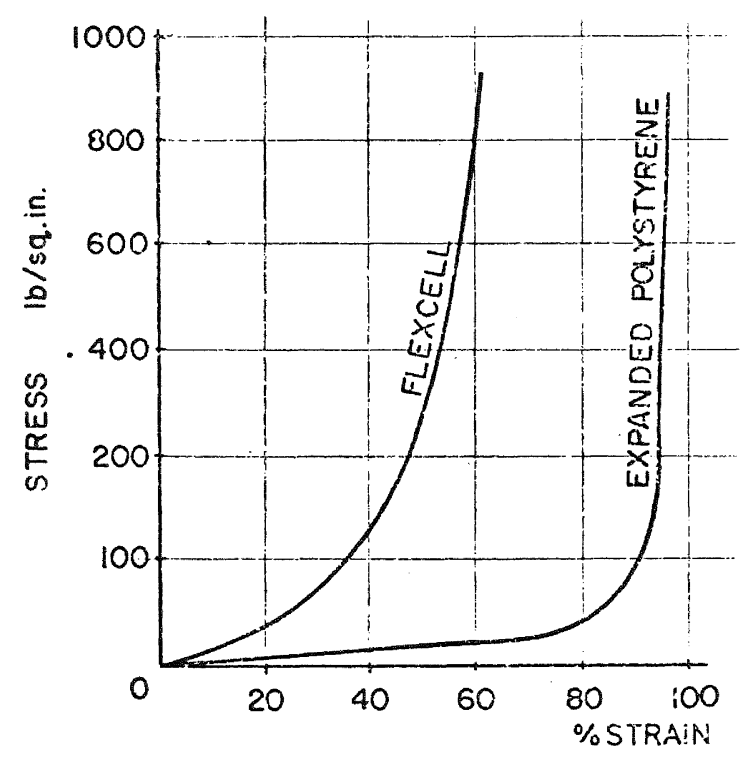

